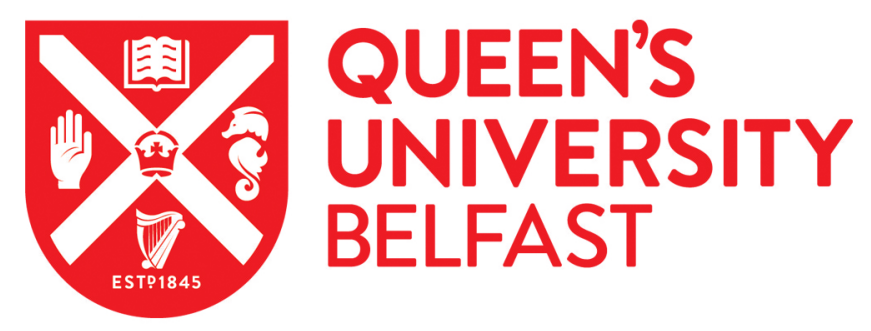

\title{
Development of Polycaprolactone-Based metronidazole matrices for intravaginal extended drug delivery using a mechanochemically prepared therapeutic deep eutectic system
}

Li, S., Culkin, A., Jones, D. S., \& Andrews, G. P. (2021). Development of Polycaprolactone-Based metronidazole matrices for intravaginal extended drug delivery using a mechanochemically prepared therapeutic deep eutectic system. International Journal of Pharmaceutics, 593, [120071]. https://doi.org/10.1016/j.ijpharm.2020.120071

Published in:

International Journal of Pharmaceutics

Document Version:

Peer reviewed version

Queen's University Belfast - Research Portal:

Link to publication record in Queen's University Belfast Research Portal

\section{Publisher rights}

Copyright 2020 Elsevier.

This manuscript is distributed under a Creative Commons Attribution-NonCommercial-NoDerivs License

(https://creativecommons.org/licenses/by-nc-nd/4.0/), which permits distribution and reproduction for non-commercial purposes, provided the author and source are cited.

\section{General rights}

Copyright for the publications made accessible via the Queen's University Belfast Research Portal is retained by the author(s) and / or other copyright owners and it is a condition of accessing these publications that users recognise and abide by the legal requirements associated with these rights.

Take down policy

The Research Portal is Queen's institutional repository that provides access to Queen's research output. Every effort has been made to ensure that content in the Research Portal does not infringe any person's rights, or applicable UK laws. If you discover content in the

Research Portal that you believe breaches copyright or violates any law, please contact openaccess@qub.ac.uk. 
1 Development of Polycaprolactone-Based Metronidazole Matrices for Intravaginal Extended 2 Drug Delivery Using a Mechanochemically Prepared Therapeutic Deep Eutectic System 3

4 Shu Li ${ }^{1,2 *}$, Alice Culkin ${ }^{1}$, David S Jones ${ }^{1}$, Gavin P Andrews ${ }^{1,2}$

5

$6{ }^{1}$ The Pharmaceutical Engineering Group, School of Pharmacy, Queen’s University Belfast, $7 \quad 97$ Lisburn Road, Belfast, Northern Ireland, UK, BT9 7BL.

$8 \quad{ }^{2}$ China Medical University - Queen's University Belfast joint College (CQC), No.77 Puhe

9 Road, Shenyang North New Area, Shenyang, Liaoning Province, P.R. China.

10

11 *Correspondence to: Dr Shu Li (Tel: +44-28-9097-2367, E-mail: s.li@qub.ac.uk) 
14 The engineering of crystalline multi-component drug systems, including cocrystals and salts, is now an established method of modifying the physicochemical properties and dissolution behaviour of an active ingredient. Remarkably, liquid drug systems, including therapeutic ionic liquids and therapeutic deep eutectic solvents (THEDES), remain largely unexplored as an untapped reservoir for drug modification. In this work, the formation of a THEDES containing metronidazole (MET), the preferred first-line treatment for bacterial vaginosis (BV), was explored. The formed THEDES was evaluated for its dissolution behaviour from a simple polycaprolactone (PCL) matrix, in order to achieve an extended release, balanced with an appropriate onset of action, hence offering improved MET intravaginal application. To minimise handling of the liquid THEDES, an end-to-end continuous process that enables feeding of the raw materials in their respective solid forms, and collection of a solidified final formulation is presented. The concurrent THEDES formation and formulation were carried out using a bench scale (approx. 10g) twin-screw hot melt extruder. The chosen parent reagents have shown sufficiently strong reactivity and resulted in successful and complete conversion to THEDES while in the presence of PCL, during the extrusion process. The formulated THEDES-PCL matrix exhibited significantly improved onset of drug release followed by a controlled delivery of MET over a total 7-day period in SVF, proving itself as a viable alternative to oral therapy.

34 KEYWORDS: Therapeutic deep eutectic, multi-component pharmaceutical materials, metronidazole, polycaprolactone, hot melt reactive extrusion, mechanochemical preparation, intravaginal delivery, antimicrobial, extended release. 


\section{INTRODUCTION}

44 Bacterial vaginosis (BV), a common type of vaginitis, is a widespread disorder of the female population and one of the most widely studied gynaecological diseases. BV can be associated with diseases such as pelvic inflammatory disease, endometritis and vaginal cuff cellulitis after invasive procedures. Unfortunately, this can lead to serious complications including stomach pain, infertility and pre-term birth (Darwish et al., 2007). Treatment regimens for BV and other common forms of vaginitis (e.g., trichomoniasis and yeast infections) are recommended to not only resolve primary symptoms, but also to reduce the risk of developing secondary sexually transmitted infections including chlamydia, gonorrhoea, trichomonas vaginalis, herpes simplex virus type 2 infections and, human immunodeficiency virus (HIV) (Jones, 2019; Myer et al., 2005). Current NICE guidelines recommend metronidazole (MET) as a preferred first-line agent for BV treatment and management (Pal et al., 2011). The Centers for Disease Control and Prevention (CDC) also recommends within sexually transmitted diseases (STD) treatment guidelines, the use of MET for those at risk of STDs due to development of BV (Centers for Disease Control and Prevention, 2015). The common regimen for such applications is either twice daily oral administration of MET $500 \mathrm{mg}$ tablets for a course of 7 days, or $0.75 \%$ MET gel used intravaginally at bedtime for 5 days. Both administration routes have been shown to offer similar therapeutic efficacies, with oral administration typically causing gastrointestinal irritation (Hanson et al., 2000). Oral MET tablets also suffer from poor patient compliance and sub-optimal performance due to additional significant adverse effects including greater prevalence of drug-drug interactions and poor patient tolerability. More recently, oral antibiotic treatments have also been reported to result in potentially unnecessary exposure to systemic antibiotics, and thus greater risks for developing antimicrobial resistance (AMR) (Smith, 2018; Turgut and Ozyazici, 2004; Zhang et al., 2013). Intravaginal delivery using gels, on the other hand offer localised targeting to the site of infection (Cunningham et al., 1994) whilst circumventing risks often associated with systemic exposure. These formulations, however, can be messy, uncomfortable, problematic in terms of drug content uniformity and suffer from formulation leakage. To address these issues and hence improve patient adherence, solid dosage forms such as vaginal tablets, suppositories and ring-shaped vaginal inserts are often used instead. However, these long-term implantable devices are typically made of either polymeric matrices that have significantly prolonged biodegradation profiles, or silicone based matrices that require removal after release of drug. 
Amongst a number of biodegradable polymeric excipients, polycaprolactone (PCL) has been studied as a promising matrix carrier for extended release intravaginal dosage forms (Dang et al., 2013; Pathak et al., 2018, 2015, 2014), owing to its biocompatible nature, its established non-toxicity to the human body (Wan et al., 2009), as well as the fact that it can be completely excreted from the human body once bioabsorbed (Ramanujam et al., 2018). PCL has also been previously formulated with MET for dental applications (Lan et al., 2013), and has been used to prepare matrices for a controlled 7-day release of tinidazole for intravaginal administration (Fernando et al., 2019). These reported formulations, however, required either the formation of a blend between PCL and a hydrophilic polymer (such as alginate), or the generation of microporous structures within the PCL architecture, to achieve suitable drug release properties. In addition to the abovementioned modifications to PCL's biodegradation profile, we propose in this work, an alternative strategy to reduce the timeline required for complete drug release from PCL matrices via modification of the active ingredient and its dissolution behaviour.

Over the last decade, there has been significant interest in the use of multicomponent drug systems as a means of offering modified drug properties and drug dissolution behaviour. Examples include pharmaceutical co-crystals, small molecule co-amorphous systems and organic pharmaceutical salts. Using these complex guest molecule/counter-ion supramolecular structures, modification of physicochemical properties such as melting point, stability, aqueous solubility and the rate of dissolution may be achieved. Traditionally, solid forms (co-crystals, salts, polymorphs and/or hydrates) of these multi-component systems have been favoured due to ease of handling and general acceptance within the industry. Interestingly, liquid counterparts are often overlooked and represent an area that requires further investigation. In particular, the scientific literature is devoid of articles describing the fundamental characterisation and behaviour of multi-component liquid systems. This may be due to a general dislike of handling liquid substances and intermediates particularly during preparation of conventional dosage forms, the requirement for atypical characterisation tools to assure product quality, and very importantly, gaps in regulatory guidelines.

Despite having a more uncertain and complex development landscape, there is growing interest in these unexplored liquid drug systems (Aroso et al., 2016; Shamshina et al., 2013; Sheldon, 2017; Stoimenovski et al., 2010). Indeed, there is evidence within the literature to suggest that these complex liquid systems represent an untapped resource for drug enablement. 
One major thrust of recent academic research has focused on liquid drug intermediates, namely

110 pharmaceutically active ionic liquids (ILs). Generally regarded as third generation ILs, these

111 complex liquid systems will involve an ionic API of interest and a second ionic component,

112 that being, a second API or a biologically inactive component, that is present to enhance the

113 physicochemical properties of the parent API. Moreover, therapeutic ILs offer zero waste and

114 leave no waste product in their synthesis, are regarded as offering significantly 'green'

115 processing, a factor that is increasingly important for an industry operating in a more socially

116 responsible environment (Sheldon, 2017). Despite their significant advantages, according to

117 the current FDA guidance, each new IL combination is considered a new chemical entity, and

118 thus requires extensive toxicological testing before use in humans (Pedro et al.,

119 2019).Therapeutic deep eutectic solvents (THEDES) (liquid equivalents to co-crystals) are a

120 relatively new class of liquid molecular adduct that are liquids at room temperature. These

121 innovative liquids consist of an intimate mixture of two components that interact through a

122 variety of non-covalent interactions, including hydrogen bonding (H-bonding) and Van der

123 Waals interactions (Abbott et al., 2017). Traditionally, a deep eutectic solvent (DES) consists

124 of a Lewis or Brønsted acid and base, such as a carboxylic acid and choline bicarbonate, which

125 strongly interact through H-bonding (Abbott et al., 2004). THEDES have been previously

126 reported, and in these cases at least one of the components in the liquid molecular adduct is a

127 pharmaceutically active ingredient (Aroso et al., 2015). Similar to solid co-crystals, which are

128 bonded via non-ionic non-covalent forces, the regulatory review and testing of THEDESs is

129 considerably more straightforward relative to therapeutic ILs. There are relatively limited

130 examples of THEDESs on the market, however there are examples of marketed eutectic

131 mixtures containing APIs. For example, EMLA® cream, which consists of an equimolar

132 mixture of lidocaine and prilocaine and used for enhanced transdermal delivery and improved

133 local absorption of both local anaesthetics (Wagner et al., 2006). Another THEDES product on

134 the market is the S-Caine ${ }^{\mathrm{TM}}$ Peel, a topical anaesthetic which contains a eutectic mixture of

135 lidocaine and tetracaine for effective pain relief for patients undergoing pulsed dye laser (PDL)

136 treatment (Bryan et al., 2002). The same equimolar mixture of lidocaine and tetracaine is also

137 marketed as Pliaglis ${ }^{\circledR}$, which is used for dermatologic laser procedures, due to its fast-acting

138 and efficacious performance (Alster, 2013).

140 When designing liquid molecular adducts such as ILs and THEDES, typical considerations

141 include the nature of the components and the predicted interactions that can occur between

142 them, through intentionally avoiding pairing components which would yield common 
143 supramolecular synthons that may lead to crystallisation. This approach adopted in selecting

144 materials has been referred to as the 'anti-crystal engineering' approach (Dean et al., 2009),

145 which avoids pairing molecules based on a supramolecular synthon approach to avoid

146 crystallisation of a solid multi-component system. As a result, design of a neutral liquid

147 molecular adduct can prove challenging due to the many possible interactions that may occur,

148 and is often based on trial and error (Cherukuvada and Nangia, 2013). In this work, a number

149 of acidic compounds (respective structures shown in Table 1), which were selected based upon

150 a set of preliminary screening criteria, were investigated for feasibility to form a THEDES with

151 MET; the structure of these compounds are shown in Figure 1. The eutectic point of the most

152 promising system, MET-maleic acid (MA), was determined using a binary thermal phase

153 diagram (Yamashita et al., 2014).

154

155 This article extends recent work within the literature and provides a means by which a

156 THEDES system may be used to offer clinically optimal dosage forms. For the first time, we report the use of THEDES technology to modify the drug release properties of MET from a

158 simple PCL matrix, to achieve a balance of rapid onset of action and an extended drug release

159 for improved MET intravaginal application. To minimise handling of the liquid THEDESs, an

160 end-to-end continuous process that enables feeding of the raw materials in their respective solid

161 forms, and collection of a solidified final formulation is described. In our previous work, we

162 have demonstrated the viability of hot-melt extrusion (HME) to offer a means by which co-

163 crystal synthesis may be achieved concurrently with drug product manufacture in a single-step

164 continuous process ( $\mathrm{Li}$ et al., 2018, 2016). Here, we extend this work by adapting HME

165 technology for the production of vaginal implant that may offer enhanced clinical performance

166 and develop an enhanced THEDES-PCL system for intravaginal delivery of MET. 


\section{MATERIALS AND METHODS}

\subsection{Materials}

Metronidazole was a kind gift from Farchemia Srl (Treviglio, Italy). Maleic acid and polycaprolactone were purchased from Sigma Aldrich (Dorset, UK). All other chemical reagents used were of analytical grade.

\subsection{Liquid-Assisted Grinding (LAG)}

LAG was used in this work to: (1) confirm the feasibility of forming a THEDES between the chosen reagents, and (2) prepare samples for subsequent thermal analysis and phase diagram construction. MET and MA were added to the ball milling chamber (MM200, Retsch, Germany) in differing molar ratios (MET:MA 9:1, 4:1, 7:3, 2:1, 1:1, 2:3, 1:2, 1:4 and 1:9) along with two drops of methanol and two $15 \mathrm{~mm}$ stainless steel milling balls. The mixtures were ground for 20 min consecutively at $22 \mathrm{~Hz}$.

\subsection{Thermogravimetric Analysis (TGA)}

The thermal stability of each compound (5 - $10 \mathrm{mg}$ ) was investigated using a Thermal Advantage model TA Q100 (TA Instruments, UK). Ramp tests were carried out at a heating rate of $10{ }^{\circ} \mathrm{C} / \mathrm{min}$ in the range of $25-300^{\circ} \mathrm{C}$. In order to maintain an inert environment, dry nitrogen was used as the purge gas at a flow rate of $60 \mathrm{~mL} / \mathrm{min}$ for the sample chamber and 40 $\mathrm{mL} / \mathrm{min}$ for the balance chamber.

\subsection{Differential Scanning Calorimetry (DSC)}

DSC (Thermal Advantage model Q20, TA Instruments, UK) was used to characterize the thermal behaviour of all raw ingredients, physical mixtures between MET and MA at various molar ratios, the liquid molecular adducts formed during LAG, physical mixtures of the extruded formulations and, the extrudates. The instrument was calibrated using indium and zinc prior to use. Samples (3 - $10 \mathrm{mg}$ ) were accurately weighed and transferred into aluminium pans which were subsequently crimped with aluminium lids. Samples were equilibrated at -65 being used as the purge gas at $50 \mathrm{~mL} / \mathrm{min}$. 
IR spectra were obtained on a Perkin-Elmer infrared spectrophotometer coupled with an

Universal ATR sampling accessory (Spectrum Two FT-IR Spectrometer, Perkin-Elmer Instruments, USA). Data was collected across a range from 4000 to $650 \mathrm{~cm}^{-1}$ at a resolution of $4 \mathrm{~cm}^{-1}$ (16 scans). Data was plotted as transmittance (\%) over wavenumber $\left(\mathrm{cm}^{-1}\right)$ and processed using Spectrum IR (Perkin-Elmer, USA).

\subsection{Hot-Melt Extrusion (HME)}

208

Physically blended mixtures of MET and MA, with and without PCL (10 and $20 \%$ w/w MET), were manually fed into a corotating twin-screw bench-top extruder (HAAKE Minilab, Staffordshire, U.K.) equipped with a $3 \mathrm{~mm}$ cylindrical die. All extrusion runs were carried out at $65{ }^{\circ} \mathrm{C}$ and $30 \mathrm{rpm}$, conditions that were driven by the processing constraints of the polymer. Drug content evaluation was carried out by dissolving $3 \mathrm{~cm}$ lengths of extrudate $(n=6)$ in dichloromethane (DCM), with the amount of drug determined using UV-Vis.

\subsection{Surface Morphology of the Extruded PCL Matrices}

Scanning electron microscopy (SEM) was used to study the surface morphology of the extruded PCL matrices. Adhesive carbon tabs were used to mount samples on aluminium pin stubs. SEM images of the extrudates were collected using a TM3030 microscope (Hitachi, Tokyo, Japan).

\subsection{Mechanical Characteristics of the Extruded PCL Matrices}

PCL matrices were fused into ring-shaped devices (outer diameter $5.4 \pm 0.1 \mathrm{~cm}$ ), and underwent compression testing using a TA.XTplus texture analyser (Stable Micro Systems, Surrey, UK). The target compression distance was set at $5 \mathrm{~mm}$, with a test speed of $2 \mathrm{~mm} / \mathrm{s}$. The maximum compression force was recorded (in Newtons) for six cycles, with the last five readings averaged to produce the result.

\subsection{In Vitro Dissolution Study}

Simulated vaginal fluid (SVF) was prepared using $3.51 \mathrm{~g} \mathrm{NaCl}, 2.00$ g lactic acid, $1.40 \mathrm{~g} \mathrm{KOH}$, hydrochloric acid solution (Owen and Katz, 1999). 
234 Capsules containing $250 \mathrm{mg}$ of MET or MET-MA 1:1 after LAG and HME, were placed in 235 bottles containing $50 \mathrm{~mL}$ of SVF and placed in an incubator shaker at $37 \pm 0.5^{\circ} \mathrm{C}$ and $40 \mathrm{rpm}$ 236 over a $2 \mathrm{~h}$ period. The dissolution medium used was $50 \mathrm{~mL}$ to imitate the maximum volume of 237 vaginal fluid produced by healthy women, who are neither pregnant nor menopausal (Owen 238 and Katz, 1999) and was carried out under non-sink conditions (MET solubility in SVF pH 4.5 239 8.97 $\pm 0.13 \mathrm{mg} / \mathrm{mL})$. Samples $(3 \mathrm{~mL}, \mathrm{n}=3$ ) were taken at predetermined time intervals and 240 replaced with fresh dissolution medium. Where extruded PCL matrices were tested, the 241 extrudate was cut into a specific length (24.6 $\pm 1.6 \mathrm{~cm}$ for $20 \% \mathrm{w} / \mathrm{w}$ MET) that contained 242 equivalent to $250 \mathrm{mg}$ of MET, bent and fused into a ring-shaped device before being placed in 243 the dissolution bottle. The concentration of MET was determined using UV-Vis at $319 \mathrm{~nm}$ 244 using a validated calibration $\left(\mathrm{y}=32.049 \mathrm{x}+0.023, \mathrm{R}^{2}=0.996\right)$.

\subsection{Statistical Analysis}

247 Results from the THEDES LAG vs HME dissolution study were statistically evaluated using a student t-test, where the level of significance was denoted as $\mathrm{P}<0.05$. 


\section{RESULTS AND DISCUSSION}

251

252

253

254

255

256

257

258

259

260

261

262

263

264

265

266

267

268

269

270

271

272

273

274

275

276

277

278

279

280

281

282

283

Formation of a multi-component molecular adduct between MET and a hydrophilic agent represents a strategy to accelerate drug release from PCL matrices, through increase of the drug dissolution rate (Zeitsch, 2000; Zheng et al., 2019). During preliminary screening for suitable coformer candidates, the following criteria were applied: (1) possessing at least one carboxylic acid group, (2) a pKa value that is $<5$, (3) having a reasonable aqueous solubility, (4) generally recognised as safe (GRAS) status.

Several short-chain fatty acids (SCFAs) and aromatic carboxylic acids that met all pre-set coformer criteria were tested for feasibility of forming a room temperature (RT) THEDES with MET (Table 1) using LAG, an established and cost-effective method of screening multicomponent molecular adducts (Hyun et al., 2019). MA was selected for further study due to its higher aqueous solubility (440.7 g/L $25{ }^{\circ} \mathrm{C}$ (Yalkowsky et al., 2010)), low acidic pKa value (1.91 (Kastelic et al., 2010)), and its capability of forming a RT liquid with MET when blended at an equimolar ratio ( $\mathrm{T}_{\mathrm{g}}$ of the formed liquid measured to be $-39.7 \pm 3.4{ }^{\circ} \mathrm{C}$, Table 2 ).

\subsection{Mechanochemical Synthesis of MET-MA THEDES via Reactive Extrusion}

MET and MA were subjected to thermal analysis and were confirmed to present completion of their respective melting event at $169.5 \pm 1.0^{\circ} \mathrm{C}$ and $152.5 \pm 2.9^{\circ} \mathrm{C}$, respectively (Table 2). The two parent reagents were mixed via LAG at molar ratios from MET:MA 1:9 ( $\chi$ MET $=0.1)$ to 9:1 $(\chi \mathrm{MET}=0.9)$. These binary blends were characterised using DSC and a temperaturecomposition phase diagram was constructed to better understand the thermal behaviour of the system. To indicate for boundary between the complete liquid phase and the solid-liquid mixed phase (the liquidus line), the end point of the last melting (Tmend) event of each system was used for the plotting of the phase diagram. As shown in Figure 2 and reported in Table 2, at $\chi \mathrm{MET}=0.9$, a depressed melting of MET was observed $\left(158.8 \pm 2.4{ }^{\circ} \mathrm{C}\right.$, as compared to $169.5 \pm 1.0^{\circ} \mathrm{C}$ for pure MET), as a result of the presence of a small quantity of MA (in accordance with the melting point depression theory). With increasing proportions of MA, further depression of the MET melt was observed with the appearance of a glass transition event at approximately $-38.9 \pm 1.9^{\circ} \mathrm{C}$. In particular, at $\chi \mathrm{MET}=0.8$, a $\mathrm{T}_{\mathrm{g}}$ at $-40.7 \pm 0.9^{\circ} \mathrm{C}$ was observed in addition to the depressed MET melting at $156.5 \pm 1.1^{\circ} \mathrm{C}$. Furthermore, at higher concentrations of MA the $T_{g}$ remained unchanged whereas the $T_{m}$ was significantly depressed $\left(\chi \mathrm{MET}=0.7, \mathrm{a} \mathrm{T}_{\mathrm{g}}\right.$ was observed at $-38.1 \pm 1.4^{\circ} \mathrm{C}$ and a $\mathrm{T}_{\mathrm{m}}$ detected at $\left.123.7 \pm 2.9^{\circ} \mathrm{C}\right)$. At $\chi \mathrm{MET}$ $=0.67$, a $\mathrm{T}_{\mathrm{g}}$ was observed at $-40.4 \pm 4.6^{\circ} \mathrm{C}$ and a $\mathrm{T}_{\mathrm{m}}$ detected at $106.6 \pm 5.0^{\circ} \mathrm{C}$. Interestingly, at 
$\chi$ MET values of $0.5,0.4$ and, 0.33 , only a single $T_{g}$ was present with no following melting, whereas as the ratio of MET decreases further (at $\chi \mathrm{MET}$ values of 0.2 and 0.1 ), the coexistence of a $T_{g}$ and $T_{m}$ were observed again. A binary phase diagram (Figure 3) was plotted using the $\mathrm{T}_{\mathrm{g}}$ values to indicate transformation from mixed state to complete glass, and the end of the final melting event (inflection temperature of the melting peak) as the liquidus line denoting the endpoint of energy exchange at the boundary between a liquid/solid mixture and complete liquid (Diarce et al., 2015). The absence of the solidus line has been reported in the literature with deep eutectic systems where the eutectic melting point is missing, yet glass transition events are detected across a range of composition ratios (Bica et al., 2011; Wang et al., 2014). In those systems, lidocaine was observed to bond with decanoic acid, oleic acid and, ibuprofen, respectively, via "strong interactions of acid and base" that at certain composition ratios, binary blends did not crystallise at all. The authors have concluded that the deep eutectic behaviour in those systems was a result of charge-assisted hydrogen bonding forming partially ionised states between the binary constituents. A similar phase diagram has been reported by Abbott et al. when complexing quaternary ammonium salts such as choline chloride, with coformers that possess proton accepting functionality (Abbott et al., 2004). The binary system presented in the current work also possesses a $\mathrm{T}_{\mathrm{g}}$ that is well below the melting point of each starting component, invariant with regard to composition and, results in a RT liquid. Each of these observations supports the conclusion that a THEDES system has formed (Bica et al., 2011). A linear extrapolation using the depressed melting points for MET and MA, respectively, was performed and the theoretical eutectic composition was found to occur at a 1:1 molar ratio of the two parent reagents.

306

FT-IR spectra (Figure 4) showed that MET exhibited a number of characteristic vibrations, including a broad O-H stretch with the peak at $3209 \mathrm{~cm}^{-1}$ accompanied by a sharp band at 3099 $\mathrm{cm}^{-1}$ denoting the aromatic $=\mathrm{C}-\mathrm{H}$ stretch, the nitrite $\mathrm{N}-\mathrm{O}$ asymmetric stretches between 1533$1484 \mathrm{~cm}^{-1}$ and, the C-N stretches between 1273-1264 $\mathrm{cm}^{-1}$ (data for $\mathrm{N}-\mathrm{O}$ and C-N stretches not shown in the presented regions), respectively. The most characteristic vibration for MA, on the other hand, was a strong $\mathrm{C}=\mathrm{O}$ stretch at $1704 \mathrm{~cm}^{-1}$ denoting the $\mathrm{H}$-bonded carbonyl groups, accompanied by a medium band at $1633 \mathrm{~cm}^{-1}$ representing the $\mathrm{C}=\mathrm{C}$ stretch (Maçôas et al., 2001). It is worth noting that in the high wavenumber region $\left(>2800 \mathrm{~cm}^{-1}\right)$ the MA carboxylic -OH bands are very weak, confirming their involvement in strong intramolecular H-bonding between the two carboxylic acid groups. Within the equimolar MET-MA THEDES, a number of unique vibrational band shifts were observed. In particular (as detailed in Table 
318 3), the -OH in MET was seen to have blue-shifted from $3209 \mathrm{~cm}^{-1}$ to $3427 \mathrm{~cm}^{-1}$, as a result of 319 breakage of the MA intramolecular bonds freeing up the hydroxyl proton (Chiarinelli et al., 320 2019). The free water content within the formed THEDES was confirmed using TGA to be less 321 than $2 \mathrm{wt} \%$ (data not shown), suggesting the occurrence of free - $\mathrm{OH}$ band was not due to the 322 presence of moisture within the sample. Changes were also observed with the MA C=O stretch, 323 where the narrow band present at $1704 \mathrm{~cm}^{-1}$ in pure MA was significantly broadened in the 324 THEDES with shift to $1712 \mathrm{~cm}^{-1}$. This broadening and shifting of the $\mathrm{C}=\mathrm{O}$ stretch may suggest 325 that, unlike the identical and symmetrical interaction patterns shared in pure MA, the two $326 \mathrm{COOH}$ groups are involved in different interaction mechanisms in the MET-MA THEDES. 327 According to Etter's rule of H-bonding (Etter, 1991), preference for interaction occurs between 328 the $-\mathrm{COOH}$ in MA and the imidazole tertiary amine (-N=) from MET, owing to preferential 329 interaction between strongest H-bond acceptor and donor. It is worth noting that an additional 330 small peak was also observed at $1580 \mathrm{~cm}^{-1}$ in the equimolar THEDES, indicating the presence 331 of ionised $-\mathrm{COO}^{-}$and formation of a charge-assisted H-bond, as opposed to a completely 332 neutral H-bond (Wang et al., 2014). The subtle blue-shift of the peak of the MA carbonyl band from $1704 \mathrm{~cm}^{-1}$ to $1712 \mathrm{~cm}^{-1}$, may suggest substitution of the intramolecular H-bonding within pure MA by the intermolecular -COOH dimer formation within the MET-MA THEDES. The simultaneous broading and weakening of the MET aromatic $=\mathrm{C}-\mathrm{H}$ stretch in the THEDES could be a result of a shared proton, with the MA carbonyl forming a $\mathrm{C}-\mathrm{H} \cdot \mathrm{O} \mathrm{H}$-bond, stabilising the neighboring $\mathrm{N} \cdot \mathrm{H}-\mathrm{O}$ bond (Steiner and Desiraju, 1999; Stuart, 2004). The 1:1 eutectic stoichiometry suggested by the binary phase diagram is also in support of the above elucidated interaction pattern.

341 Owing to the scalability and continuous manner of manufacturing, HME has recently been shown as an efficient means of mechanochemical synthesis for viscous liquid molecular adducts including ILs and DESs. James et al recently used HME to produce a well-known choline chloride-urea DES, and showed that this method of manufacture was advantageous as it shows potential to overcome difficulties, such as loss of material in transfer, which could arise from handling highly viscous materials (Crawford et al., 2016). In the current study, a binary physical blend of equimolar MET and MA was also subjected to HME processing. A relatively low extrusion temperature, $65{ }^{\circ} \mathrm{C}$, was chosen to minimise possible influence of extensive thermal input, whilst also enabling processability of the polycaprolactone matrices in latter studies. The synthesised THEDES was collected as liquid drops at the end of the extruder barrel. 
353 It was interesting that although IR spectra of the extruded MET-MA THEDES showed identical

354 band shifts to that prepared using LAG (Figure 5), the $T_{\mathrm{g}}$ of the extruded equimolar binary 355 liquid, unlike that of the LAG counterpart $\left(-39.7 \pm 3.4^{\circ} \mathrm{C}\right.$ ), was observed at $-19.3 \pm 2.0^{\circ} \mathrm{C}$ (Figure 356 6). It was also noticed that the HME product was considerably thicker in texture and cloudier 357 looking (with visibly observable particulates suspended within the liquid) when compared to 358 the LAG counterpart. It is worth noting that the extent of $\mathrm{H}$-bonding has been reported to inversely correlate with the $\mathrm{T}_{\mathrm{g}}$ of the formed systems (Taylor and Zografi, 1998). H-bonding and the THEDES formation may have occurred to a lesser extent throughout the HME process, due to the non-intermeshing nature of the extruder used resulting in a sub-optimal mix between both components. Additionally, the presence of a small amount of residual MeOH from LAG may also contribute to a further depressed $\mathrm{Tg}_{\mathrm{g}}$ in the LAG system. As MET and MA spontaneously form a liquid adduct during extrusion under the chosen processing conditions, the binary system loses interparticular friction upon liquification. It is also worth mentioning that an endothermic event was observed for the equimolar MET/MA THEDES prepared using both LAG and HME between $120-150^{\circ} \mathrm{C}$ (Figure 6). This was due to the inherent instability of maleic acid under elevated temperature conditions to form maleic anhydride and the subsequent loss of water during the acid-to-anhydride conversion. To enable adequate mixing within a liquid, high speed agitation is usually required. However, a relatively low screw speed of $30 \mathrm{rpm}$ was used in this study, in order to attain a balance between the time the processed materials reside within the extruder and extent of mixing within the system. A short residence time within the extruder barrel results in inadequate mixing and insufficient interactions, while a lengthy residence time can lead to thermal degradation. The addition of PCL into the extrusion as a matrix carrier and processing aid was found to improve mixing intensity, which was lost in the low viscous THEDES only system.

\subsection{End-to-End Single-step Preparation of THEDES-PCL Matrices} Whilst proven processable using HME for scalable and continuous mechanochemical preparation, THEDESs, as viscous liquid drug product intermediates, can bring challenges to downstream handling. In our previous publications, we have reported that the presence of an excipient melt pool could facilitate favourable mixing between parent cocrystallisation reagents by offering a non-complimentary dispersion medium for improved inter-species molecular interactions ( $\mathrm{Li}$ et al., 2018, 2016). We also suggested that an appropriate carrier excipient should exhibit rapid solidification upon cooling post extrusion, so that a formulated 
matrix wherein cocrystals are suspended, thus negating the handling of intermediate drug product. It was, therefore, attempted in the current work to remove in-process handling through development of an end-to-end single-step HME process for THEDES embedded PCL matrices.

Physical blends of MET, MA (amount equating to a 1:1 molar ratio with respective MET loading) and PCL, at weight fractions of 10 and $20 \mathrm{w} / \mathrm{w} \%$ MET, were processed via HME using the same extrusion settings described previously $\left(65^{\circ} \mathrm{C}, 30 \mathrm{rpm}\right)$. For comparison purposes, binary formulations containing only MET and PCL were also extruded using the same conditions.

PXRD and thermal analysis (Figure 7) suggested that the MET in the MET-PCL binary extrudate had been dispersed within the PCL matrix. This was evident from the significant weakening of the MET melting peak with a noticeable depression of the onset of melting in both the physical mixture and the melt extrudates of the binary MET-PCL blend (Figure 7a), possibly owing to the low melting temperature and low melt viscosity of PCL. The presence of a small residual melting endotherm of MET, however, indicates that such dispersion was incomplete, leaving small amounts of crystalline MET within the PCL melt pool. Interestingly, such trace amount of residual MET crystallinity was not observed in the PXRD patterns (Figure 7b), possibly due to a number of reasons such as the percentage crystallinity and/or the size of remaining crystallites being below the detection limit. When MA was introduced to the system and a ternary MET-MA-PCL blend was extruded, a $\mathrm{T}_{\mathrm{g}}$ was observed in the extrudates at $38.2 \pm 1.1^{\circ} \mathrm{C}$, indicating that THEDES formation was indeed successful in the presence of PCL (Figure 8). It is notable that the observed THEDES $\mathrm{T}_{\mathrm{g}}$ within the THEDES-PCL matrix was similar to that resulted from binary THEDES LAG. Such result suggests that the addition of PCL indeed enabled improved mixing and interactions between MET and MA, possibly through added inter-particulate friction and prolonged residence time (296 $\pm 23 \mathrm{~s})$. The peak melting temperature of PCL $\left(62.2 \pm 0.2{ }^{\circ} \mathrm{C}\right)$ was also shown to be depressed to $54.4 \pm 0.3{ }^{\circ} \mathrm{C}$ in the THEDES-PCL extrudate (Figure 8). This decrease in the melting point of PCL is an additional indication of favourable mixing and miscibility between the THEDES and PCL (Rim and Runt, 1984).

IR spectra of the PCL extrudates (Figure 9) indicated that the characteristic peaks of the pure MET-MA THEDES, such as those seen at $3427 \mathrm{~cm}^{-1}, 1712 \mathrm{~cm}^{-1}, 1619 \mathrm{~cm}^{-1}$ and $1580 \mathrm{~cm}^{-1}$ and described above (Table 3), were also observed in the THEDES-PCL matrices at $3436 \mathrm{~cm}^{-1}$, 
$4201719 \mathrm{~cm}^{-1}, 1618 \mathrm{~cm}^{-1}$ and $1586 \mathrm{~cm}^{-1}$, respectively. This data further confirmed that the

421 THEDES formation was not inherently affected by dispersion within an extrudable polymeric

422 carrier. The presence of these peaks and the fact that no melting was observed for either pure

423 MET or MA in the DSC thermogram of the extrudate, could be attributed to successful and

424 complete THEDES conversion.

425

426 Mechanical stress testing was carried out on the extruded matrices once they had been fused 427 into ring-shaped vaginal inserts (Figure 10). The compression characteristics of vaginal inserts 428 is extremely important in order to ensure comfort and to prevent damage to the local mucosal 429 tissue (Promadej-Lanier et al., 2009). It has been reported in the literature that poor flexibility 430 of vaginal inserts could result in irritation to, as well as erosion and ulceration of the vaginal 431 mucosa and submucosal tissue (Mishell and Lumkin, 1970). In the current study, the 432 flexural/compressive characteristics of the prepared ring-shaped prototype inserts were 433 examined using a compression test. It was anticipated that a higher force required to compress 434 the fused devices would translate to a stiffer ring. As shown in Figure 11, the average maximum 435 compression force for the $20 \% \mathrm{w} / \mathrm{w}$ MET loaded MET-PCL and THEDES-PCL inserts were $4363.66 \pm 0.02 \mathrm{~N}$ and $1.08 \pm 0.01 \mathrm{~N}$, respectively. It is interesting that both results showed better 437 flexibilities than contraceptive vaginal rings currently on the market (Welsh et al., 2019). This 438 could be due to the fact that the prepared prototypes both had a significantly smaller cross439 sectional diameters by comparison to commercial products such as Nuvaring ${ }^{\circledR}$, Estring ${ }^{\circledR}$, and 440 Femring ${ }^{\circledR}$. The MET alone prototype ring, however, exhibited a 3-folded stiffness and multiple 441 sharp bends along the circumference when compared with the THEDES-loaded counterpart. 442 Such results suggest potential negative impact on the rings' mechanistic characteristics with 443 the incorporation of high melting point drugs within PCL matrices, particularly at elevated drug 444 loadings. The incorporation of those drugs through the use of THEDES technology, therefore, 445 could widen formulation design windows by offering considerably improved flexibility and 446 smoothness when squeezed.

\subsection{In vitro Dissolution Study}

449 Currently marketed intravaginal dosage forms include emulsions, suspensions, ointments, creams, inserts (tablets and capsules), foams and the more advanced insertable devices (i.e., vaginal rings). The targeted timeframe for the course of drug delivery also ranges from immediate release (IR) to extended release (ER) over several days, weeks or even months.

453 Release from a drug-containing matrix is influenced by various factors, including the 
dissolution behaviour of the drug itself and how the drug is dispersed throughout the polymeric matrix. The release of the drug will depend both on the surface area of the drug-containing matrix which is exposed to the dissolution medium, and also the quantity of drug loaded into the matrix (Fernando et al., 2019). For inserts designed with ER profiles, not only is an extended drug release duration required, an initial burst release that gives rise to therapeutically effective drug concentrations at the targeted site is also of paramount importance (Wu and Grainger, 2006) Owing to the inherent hydrophobic nature and extremely slow biodegradation profile, PCL remains much less explored as a drug delivery matrix carrier, when compared with other aliphatic polyesters such as polyglycolide, polylactide, poly-(lactide-co-glycolide) (PLGA), poly(hydroxyl butyrate) and, polydioxanone. One major concern for PCL-based drug delivery platforms is their slow onset of drug dissolution, leading to significant lags in offering therapeutic efficacy. It was intended in the current work, by complexing MET with a highly soluble dicarboxylic acid (MA $\mathrm{H}_{2} \mathrm{O}$ solubility $0.79 \mathrm{~g} / \mathrm{L}$ (Zeitsch, 2000)), to achieve faster and to a higher extent, MET release from the PCL matrices and into the dissolution medium, whilst also maintaining a prolonged drug release profile over a course of 7 days.

The extruded PCL matrices were tested to show an embedded MET content of $94.44 \pm 8.49 \%$ and $97.05 \pm 5.58 \%$, for extrudates consisted of only MET-PCL and the MET-MA THEDESPCL, respectively, demonstrating good uniformity of content. The drug release profile comparing the dissolution of pure MET with that of the neat THEDES (both from LAG and HME) in SVF (Figure 12), showed significantly increased onset and rate of MET dissolution from the RT liquid THEDESs. It can be noted from Table 4 that the THEDESs reached greater than $80 \%$ w/w MET dissolution within 20 min, whilst pure MET powders resulted only $1.3 \pm$ $0.1 \% \mathrm{w} / \mathrm{w}$. Such results support the hypothesis that incorporation of MA can successfully enhance the rate of MET dissolution, possibly owing to the fact that the complex formed is already in the liquid state.

It is also worth noting that, in the first $10 \mathrm{~min}$, THEDES manufactured by HME exhibited an even more significant increase in dissolution rate with a $\mathrm{DP}_{10 \min }$ of $69.3 \pm 6.9 \%$, compared to a $\mathrm{DP}_{10 \min }$ of $36.8 \pm 10.8 \%$ from the LAG THEDES. It is possible that the insufficient H-bonding between MET and MA after HME was actually responsible for this instant burst of MET dissolution, as the breaking of $\mathrm{H}$-bonds (which requires both energy and time) was possibly a rate-limiting factor in the process of MET release from the THEDES. Such a dissolution rate difference between HME and LAG THEDEs became less significant upon time and after 20 
min, there was no significant different between both THEDES dissolution profiles $(\mathrm{P}=0.67)$

489 (Figure 12). This again suggests that higher extent of H-bonding presents a kinetic barrier to 490 MET release, which might be useful in maintaining a prolonged release profile after the initial 491 burst stage.

492

493 Release of MET from the PCL matrices is driven by a number of variables, including the 494 loading of MET, porosity of the PCL matrix, solubility of MET in the dissolution medium, and 495 the rate of MET diffusion throughout the PCL pores. The release profiles of THEDES-PCL 496 extrudates, showed both increased initial dissolution rates and extented release of MET release 497 relative to MET-PCL counterparts, throughout a course of 7 days (Figure 13). It was 498 particularly promising that the THEDES-PCL matrix containing $20 \% \mathrm{w} / \mathrm{w}$ MET was capable 499 of a 'burst release' phase, releasing up to 36.0 $\pm 0.2 \%$ of the loaded MET by end of the first day

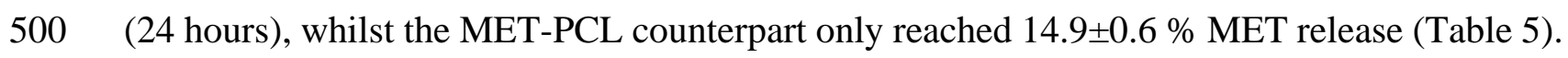
501 By end of day 2 the $20 \%$ w/w THEDES-PCL ring exceeded > $50 \%$ MET release, yet the other 502 rings exhibited significant and undesirable stagnant drug release with hardly much increase in 503 drug percentage compared with the previous day. Such a stagnation could be detrimental to 504 achieving a successful BV treatment, as the lack of boosting doses will result in insufficient 505 bactericidal effects, sustained low concentrations of antibiotic and as a result, leading to increased risks of developing antibiotic resistance in the case where local antibiotic dosing is below the mutation prevention concentration (MPC) threshold (Raymond, 2019). In the case of both the MET-PCL and THEDES-PCL matrices, at lower drug loadings of $10 \% \mathrm{w} / \mathrm{w}$ MET, the release of MET was a more gradual process as this lesser MET content reduced the concentration gradient required for Fickian diffusion (Dang et al., 2013). In the higher loaded $20 \% \mathrm{w} / \mathrm{w}$ MET systems, increasing numbers of channels and interconnected pores are to be expected as a result of microcracking effects, which enhances the dissolution rate through

513 facilitating transport of MET through the PCL matrix and into the dissolution medium (Pathak

514 et al., 2014). The remainder of the loaded MET dose within the $20 \% \mathrm{w} / \mathrm{w}$ THEDES-PCL ring 515 was seen to have been gradually released after day 2 in a zero-ordered fashion $\left(R^{2}=0.94\right)$ until 516 end of the experiments (day 7). 


\section{CONCLUSION}

518 This work demonstrated how THEDESs can be used to improve the dissolution rate of an API

519 within a small volume of liquid (non-sink conditions) in order to simulate conditions in the

520 vaginal cavity. Liquid molecular adducts would traditionally be considered as difficult to

521 handle and formulate, due to their highly viscous nature, and subsequently discarded. However,

522 this work proposes an end-to-end preparation of the formulated THEDES into a solid vaginal

523 insert, which circumvents intermediate handling and material transfer steps. The concurrent

524 THEDES synthesis and formulation were carried out using a small scale $(\approx 10 \mathrm{~g})$ bench-top

525 melt extruder with basic screw configurations, suggesting promising potential for scaled-up

526 preparations. However, it should be reiterated that the presented formulation strategy does not

527 warrant success unless the reactivity between the THEDES reagents is proven to show

528 preference to interactions between either of the parent reagents and the chosen carrier excipient.

529 The formulated THEDES-PCL matrices resulted in a controlled delivery of MET over 7 days

530 in SVF, proving itself as a viable alternative to oral therapy. Further studies will include

531 investigating the effect of loading a liquid multi-component system into a polymeric excipient

532 on the mechanical properties of the resulting matrix, as well as studies into the stability and

533 shelf-life of these THEDESs. 
(a)

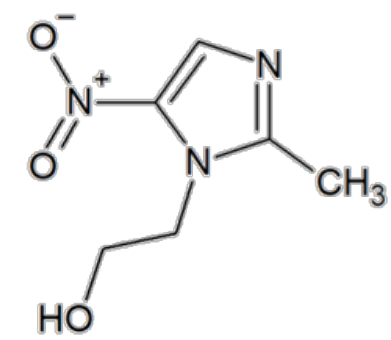

(b)

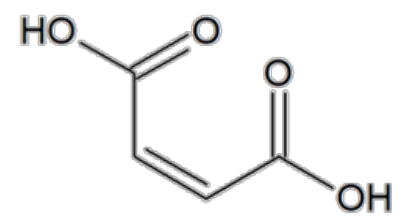

(c)<smiles>CCOC(=O)CCCCCOC(C)(C)C</smiles>

(d)

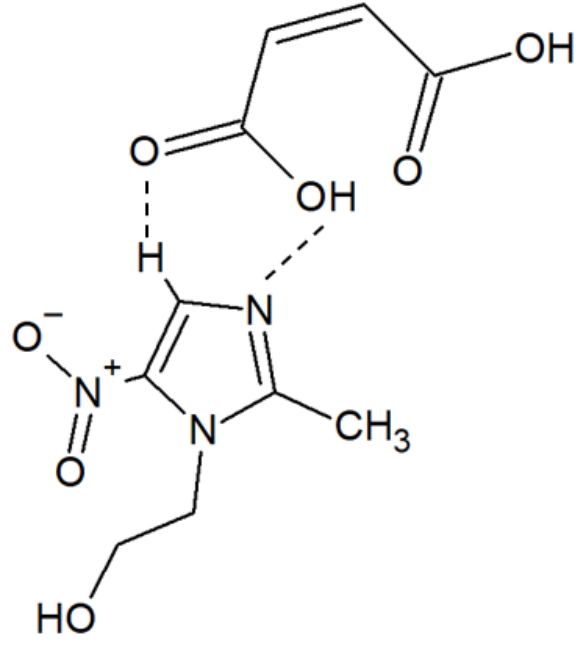




$$
\begin{aligned}
& - \text { Metronidazole } \\
& -\chi \mathrm{MET}=0.9 \\
& -\chi \mathrm{MET}=0.8 \\
& -\chi \mathrm{MET}=0.7 \\
& -\chi \mathrm{MET}=0.67 \\
& -\chi \mathrm{MET}=0.5 \\
& -\chi \mathrm{MET}=0.4 \\
& -\chi \mathrm{MET}=0.33 \\
& -\chi \mathrm{MET}=0.2 \\
& -\chi \mathrm{MET}=0.1 \\
& -\mathrm{Maleic} \text { Acid }
\end{aligned}
$$

Figure 2 DSC thermograms of (from top to bottom) MET, MET-MA $\chi M E T=0.9,0.8,0.7,0.67,0.5,0.4,0.33,0.2$ and 0.1 physical mixtures and MET, after equilibration at $-65^{\circ} \mathrm{C}$ and heating at $10^{\circ} \mathrm{C} / \mathrm{min}$ to $200{ }^{\circ} \mathrm{C}$. The highlighted region is a zoomed in area to show the $T_{g}$ of the $\chi M E T=0.8,0.7,0.67,0.5,0.4,0.33$ and 0.2 physical mixtures.
541

542

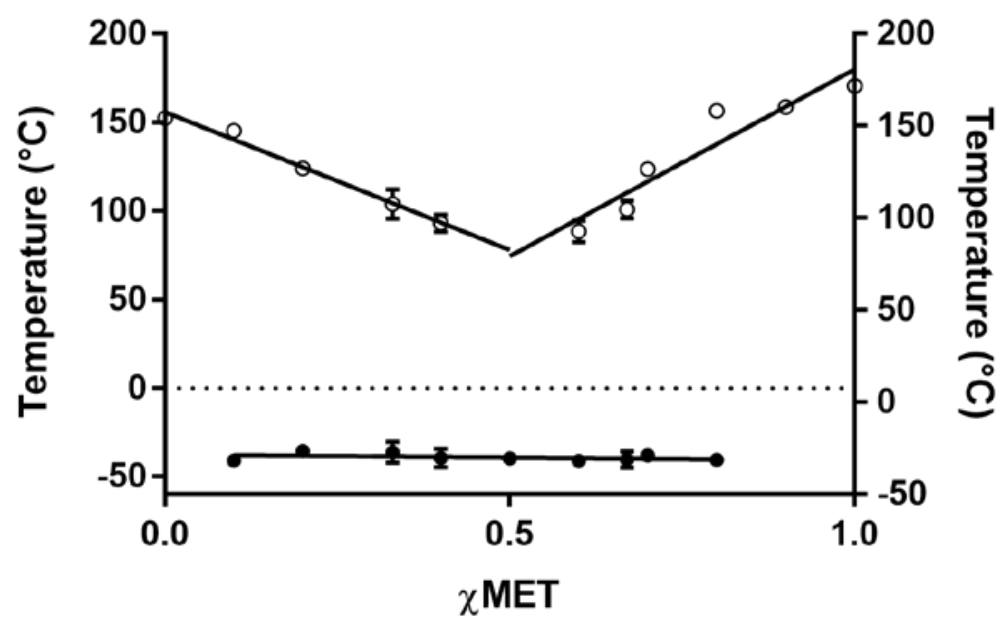

$\rightarrow T_{g}$ of Binary Mixtures

- Liquidus

544 Figure 3 Phase diagram of MET-MA system, with liquidus shown as open circles and the $T_{g}$ of the binary mixtures shown as 545 filled circles; each plot is the average of three replicates. 

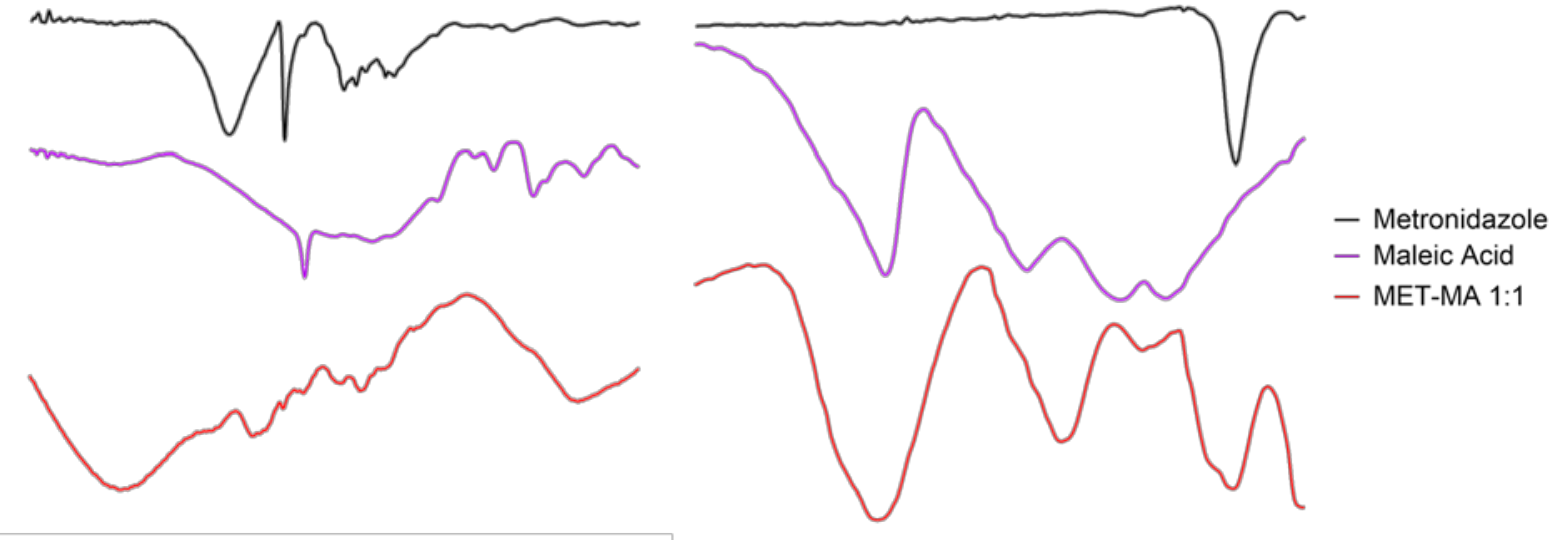

- Maleic Acid

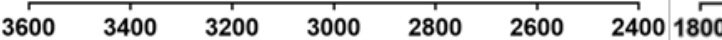

1700

1600

1500

Wavenumber $\left(\mathrm{cm}^{-1}\right)$

Wavenumber $\left(\mathrm{cm}^{-1}\right)$

Figure 4 Overlaid FT-IR spectra in the region of $1800-1500 \mathrm{~cm}^{-1}$ and $3600-2400 \mathrm{~cm}^{-1}$ of (from top to bottom) MET, MA and MET-MA 1:1 THEDES produced using LAG.
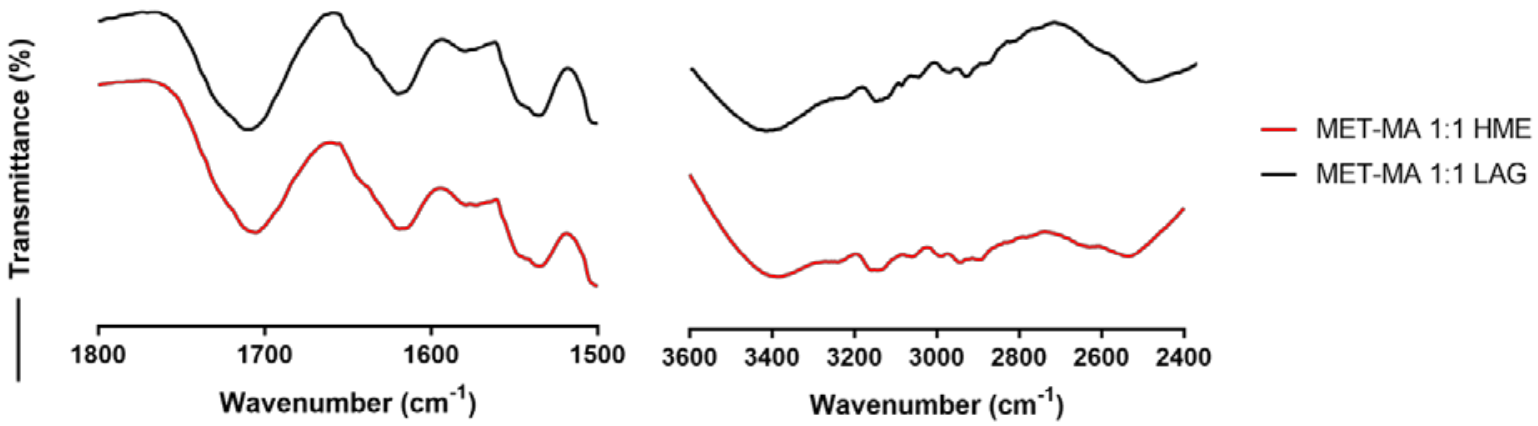

Figure 5 Overlaid FT-IR spectra in the region of $1800-1500 \mathrm{~cm}^{-1}$ and $3600-2400 \mathrm{~cm}^{-1}$ of (from top to bottom) MET-MA

553

554

(a)

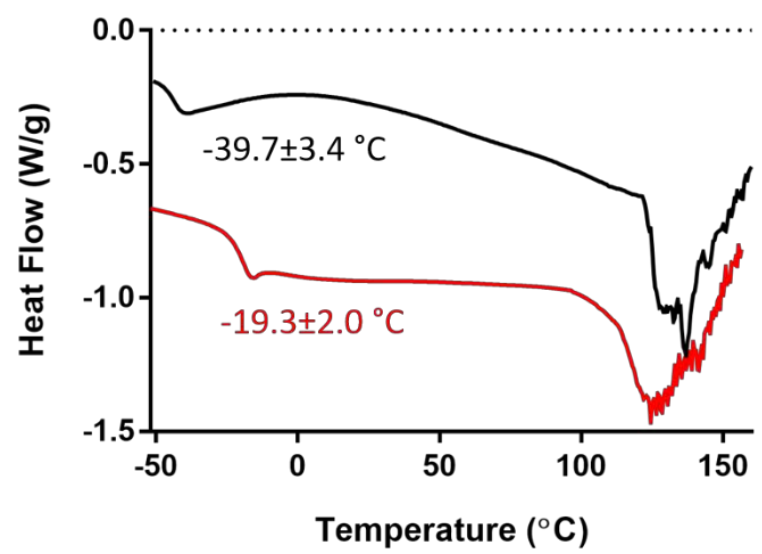

(b)

(i)

(ii)

(iii)

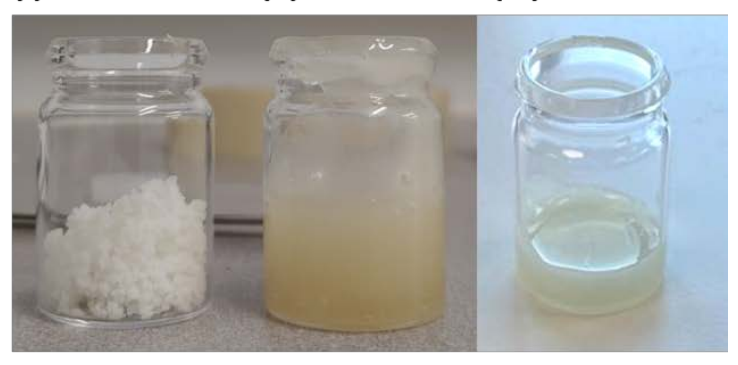

Figure 6 (a) DSC thermogram of MET-MA 1:1 after LAG (black line), and after extrusion at $65^{\circ} \mathrm{C}$ and $30 \mathrm{rpm}$ (red line) and (b) appearance of (i) the physical mixture of an equimolar MET-MA blend and (ii) product after equimolar MET-MA neat extrusion and, (iii) product after equimolar MET-MA LAG. 
(a)

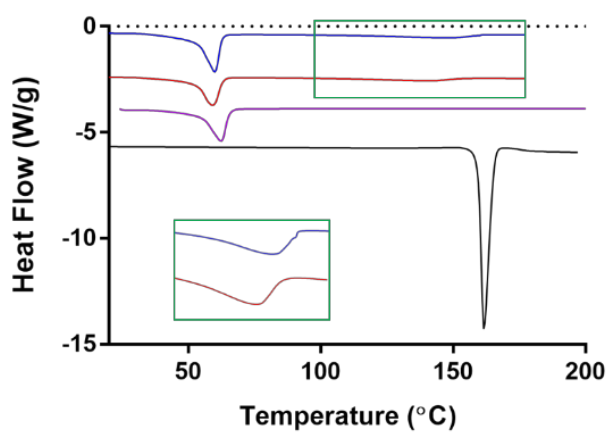

(b)

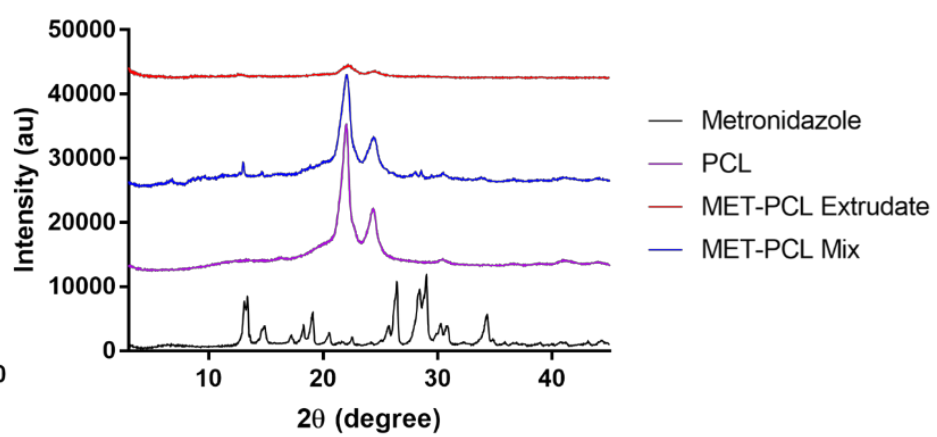

561

563

564

565

566

567

Figure 7 (a) DSC thermograms and (b) PXRD patterns of (from top to bottom), (MET-PCL) physical mixture and extrudate containing $20 \% \mathrm{w} / \mathrm{w}$ MET, PCL and MET. The area highlighted shows the shifted melting point of MET after extrusion.

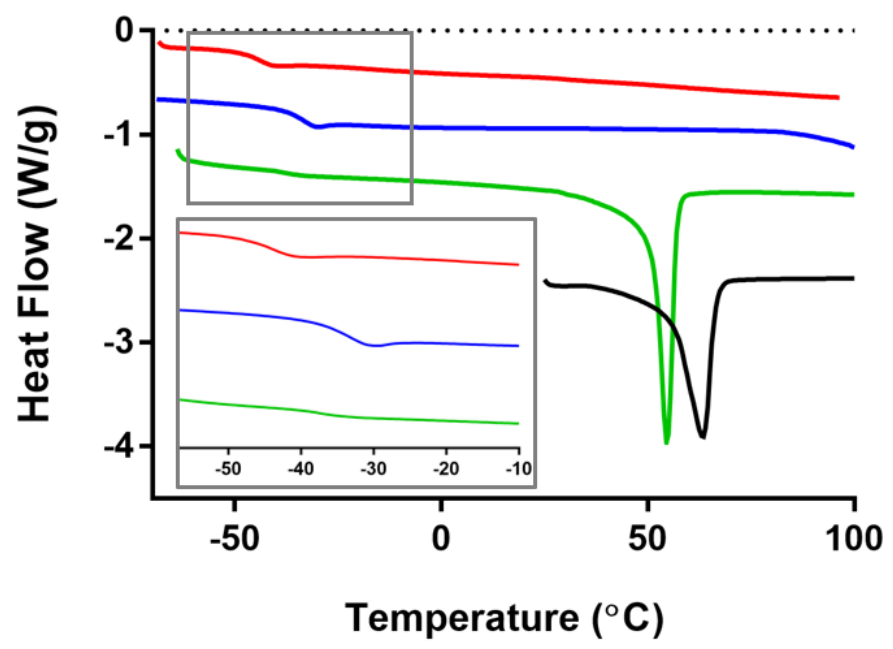

- MET-MA 1:1 Mix

- MET-MA 1:1 Extrudate

— (MET-MA 1:1)-PCL Extrudate

- PCL

Figure 8 DSC thermograms of MET-MA 1:1 physical mixture and after extrusion, (MET-MA 1:1)-PCL extrudate containing $20 \% \mathrm{w} / \mathrm{w}$ MET and pure PCL. The area highlighted in the grey box shows the $T_{g}$ of the MET-MA 1:1 DES. 

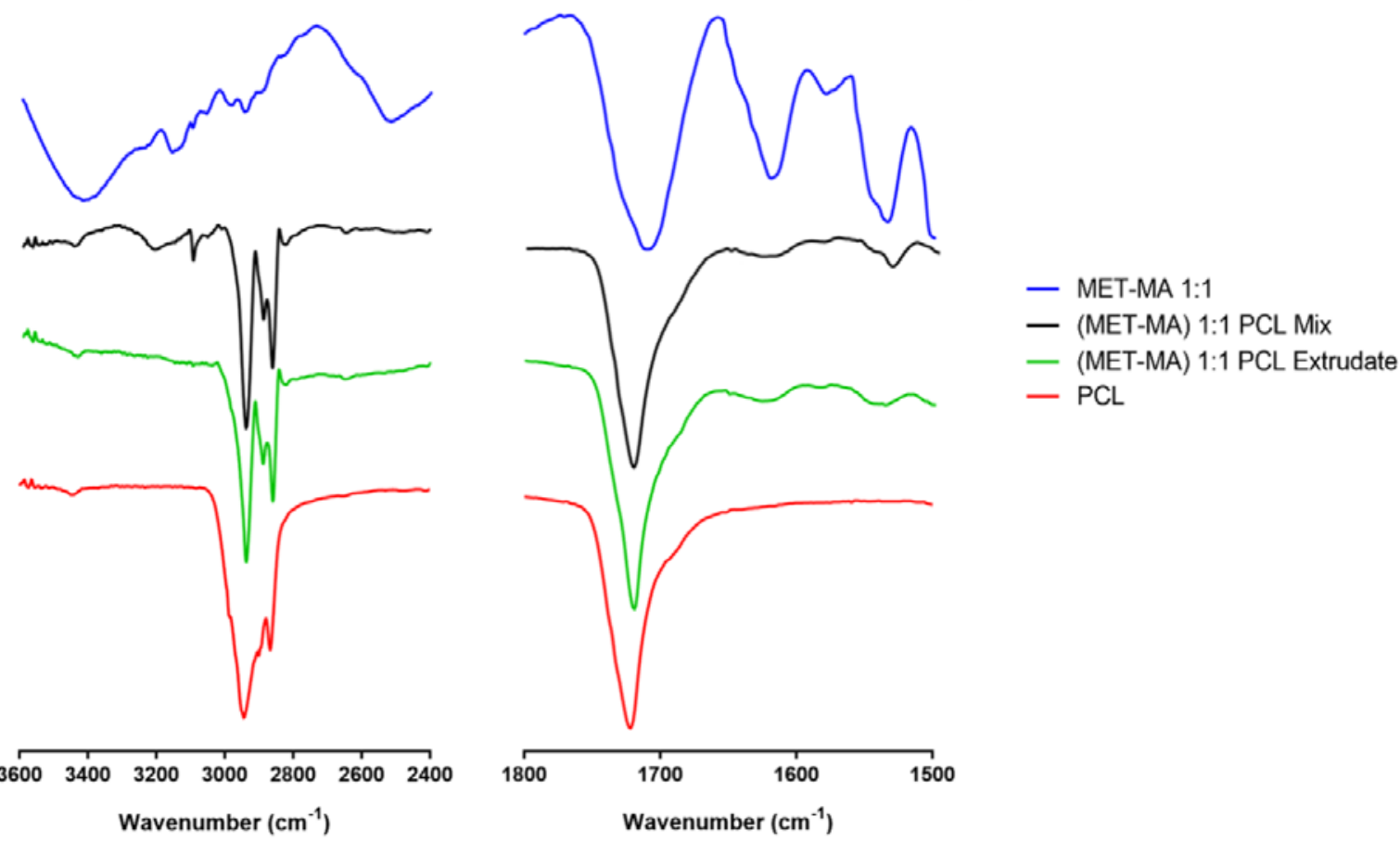

MET-PCL 20wt\% MET
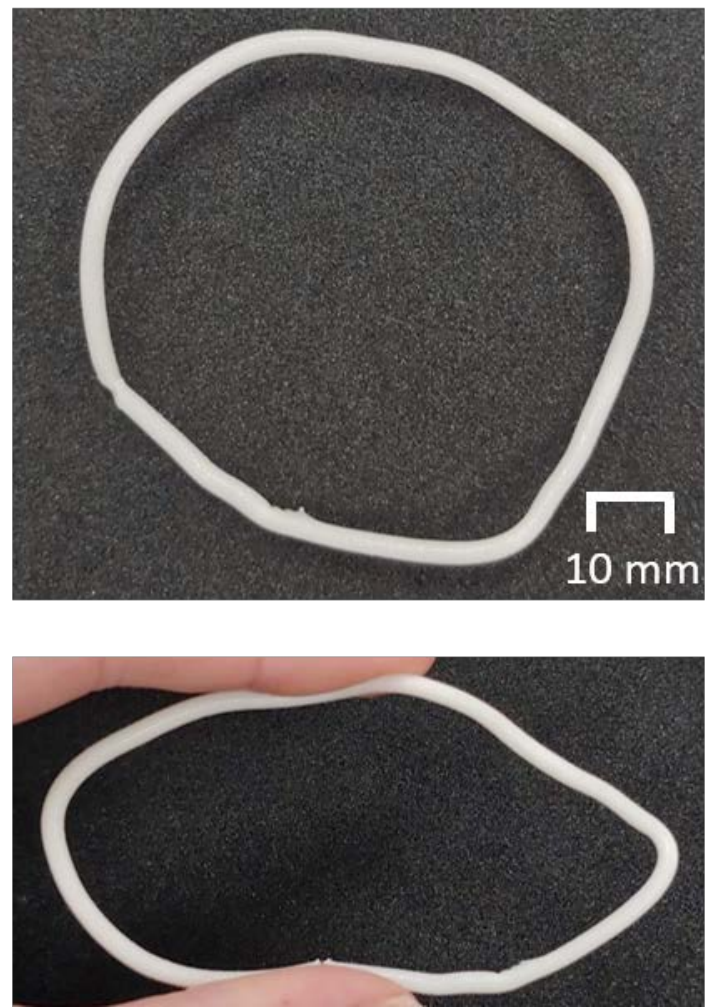

\section{MET-MA-PCL 20wt\% MET}
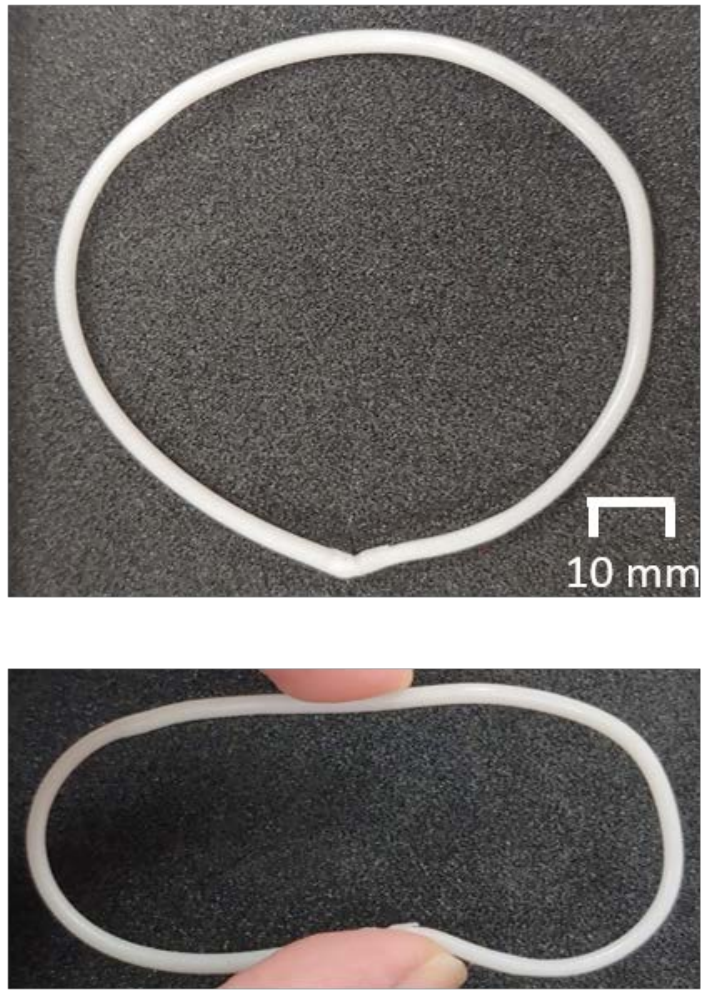

Figure 10 Photographs depicting MET-PCL and THEDES-PCL loaded matrices, respectively, containing $20 \% \mathrm{w} / \mathrm{w}$ MET, 


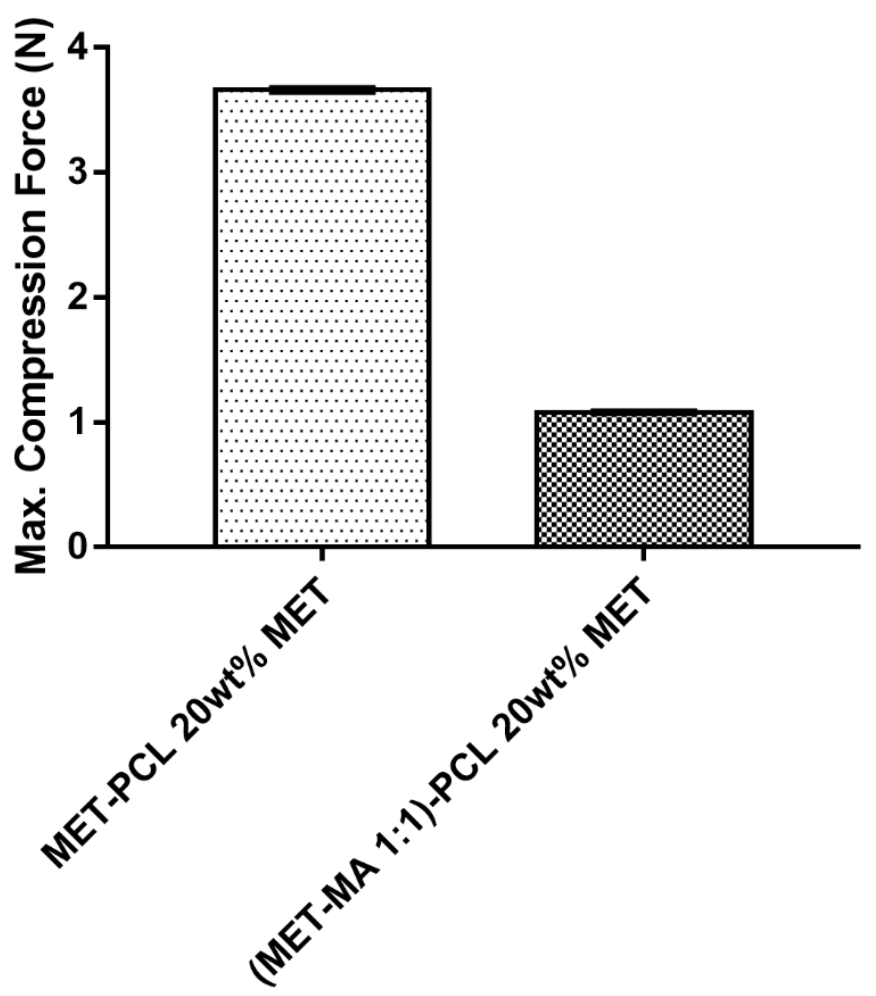

Figure 11 Average maximum compression force (N) for MET-PCL $20 \%$ w/w MET and (MET-MA 1:1)-PCL $20 \%$ w/w MET where $n=3$.

579

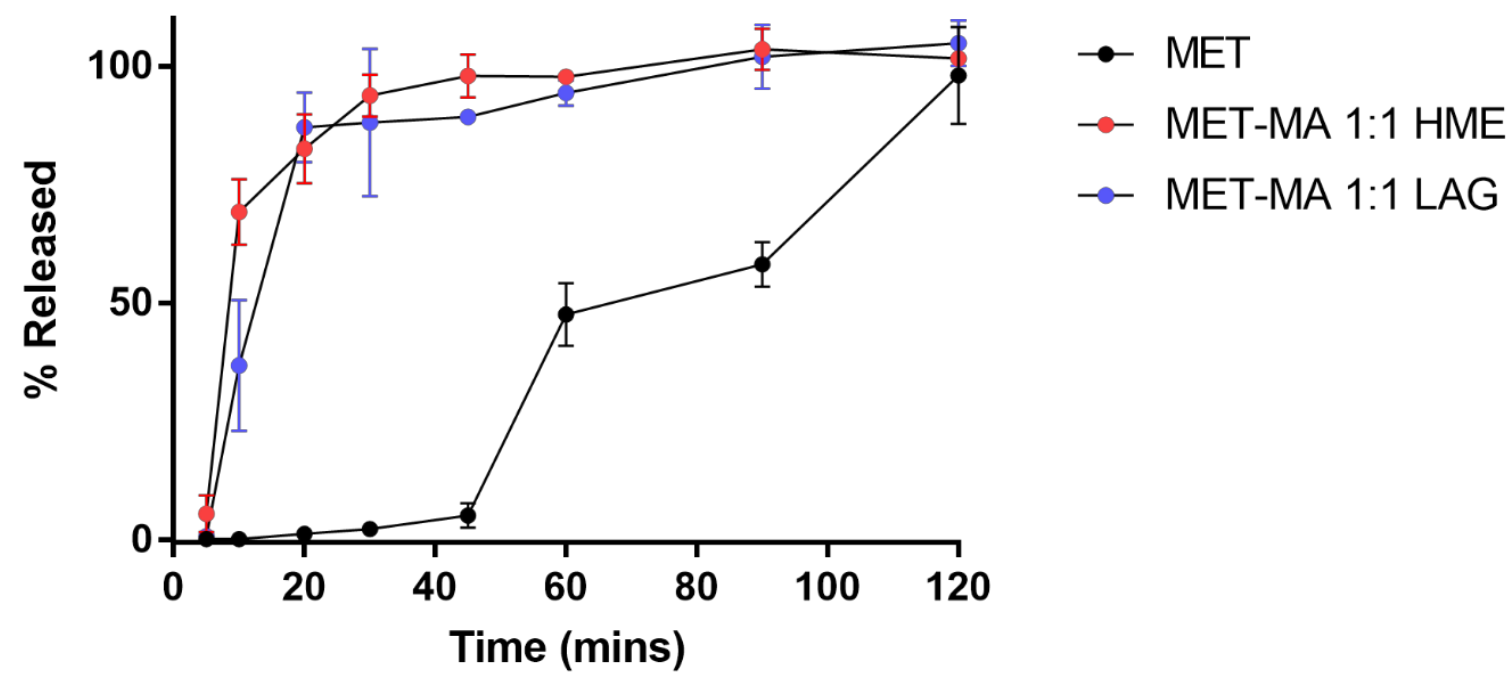

Figure 12 Dissolution profiles of MET and MET-MA 1:1 after synthesis through LAG (20 min $22 \mathrm{~Hz})$ and $\mathrm{HME}\left(65^{\circ} \mathrm{C}\right.$, 30 


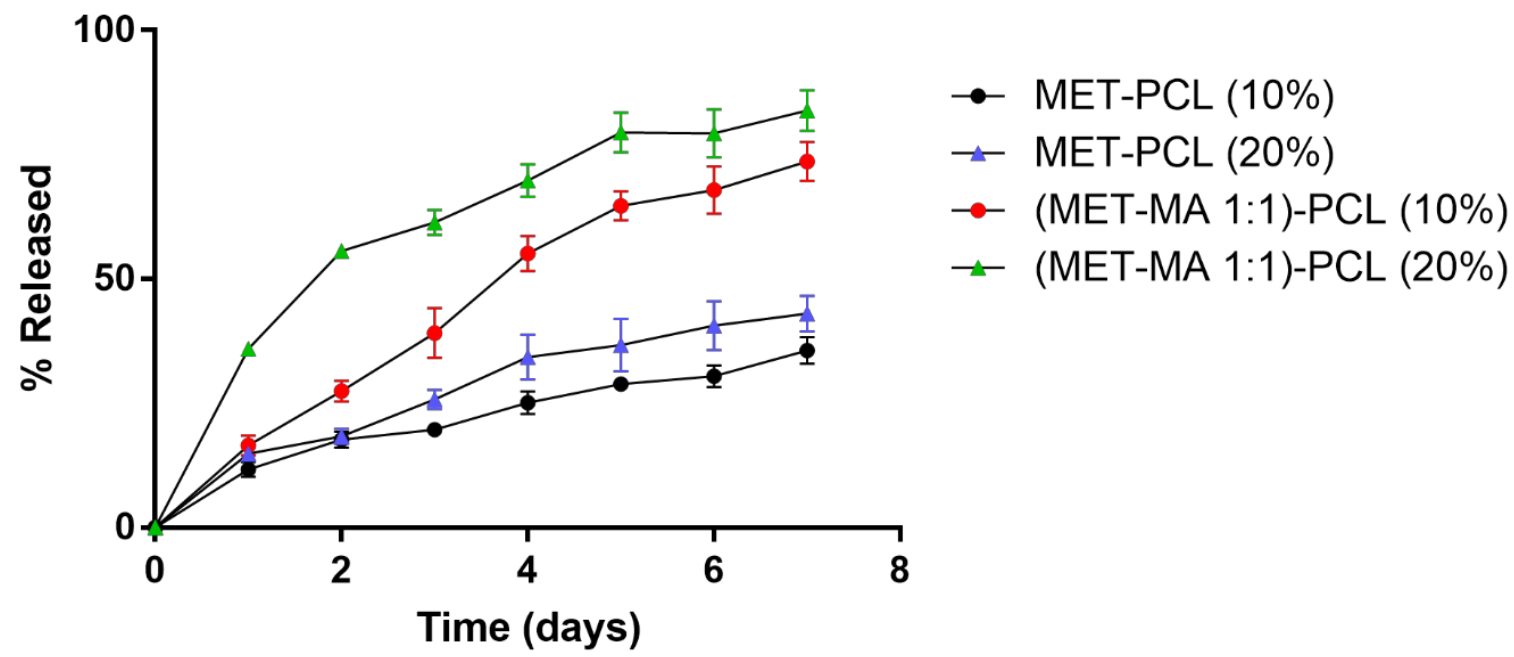

Figure 13 Dissolution profiles of melt extruded MET-MA 1:1 formulations in PCL using simulated vaginal fluid. Black and red circles represent MET-PCL and (MET-MA 1:1)-PCL at $10 \% \mathrm{w} / \mathrm{w}$ MET respectively and blue and green triangles represent MET-PCL and (MET-MA 1:1)-PCL at $20 \% \mathrm{w} / \mathrm{w}$ MET respectively. Each point is representative of the mean \pm 589 S.D. where $n=3$. 


\section{TABLES}

Table 1 Carboxylic acids that were trialled for formation of a low melting 1:1 molecular adduct with MET, including their name, structure, pKa, aqueous solubility ( $\mathrm{g} / \mathrm{mL}$ ) and the melting point or glass transition of the adduct formed after LAG for 5 minutes at $20 \mathrm{~Hz}$

\begin{tabular}{|c|c|c|c|c|c|}
\hline Acid Name & Structure of Acid & pKa & $\begin{array}{l}\text { Aqueous } \\
\text { Solubility at } 25 \\
{ }^{\circ} \mathbf{C}(\mathbf{g} / \mathrm{L}) \\
\text { (Yalkowsky et al., } \\
2010)\end{array}$ & $\begin{array}{l}\text { Peak of acid } \\
\text { melt }\left({ }^{\circ} \mathrm{C}\right)\end{array}$ & $\begin{array}{l}\mathrm{Tm} / \mathrm{Tg} \text { of } 1: 1 \\
\text { molecular adduct } \\
\left({ }^{\circ} \mathrm{C}\right)\end{array}$ \\
\hline Maleic Acid (MA) & & $\begin{array}{l}\text { 1.9, } 6.3 \\
\text { (Kastelic et al., } \\
2010 \text { ) }\end{array}$ & 440.7 & $134.3 \pm 1.1$ & $T_{g}-39.7 \pm 3.4$ \\
\hline $\begin{array}{l}\text { Azelaic Acid } \\
\text { (AZE) }\end{array}$ & & $\begin{array}{l}\text { 4.5, } 5.5 \\
\text { (Martins et al., } \\
\text { 2016) }\end{array}$ & 2.4 & $109.9 \pm 0.8$ & $\mathrm{~T}_{\mathrm{m}} 98.6 \pm 0.1$ \\
\hline Benzoic Acid (BA) & גר & $\begin{array}{l}4.2 \\
\text { (Hollingsworth } \\
\text { et al., 2002) }\end{array}$ & 3.4 & $123.1 \pm 1.3$ & $\mathrm{~T}_{\mathrm{m}} 98.0 \pm 0.4$ \\
\hline $\begin{array}{l}\text { 4-Hydroxybenzoic } \\
\text { Acid (4-HBA) }\end{array}$ & & $\begin{array}{l}3.6 \\
\text { (Hollingsworth } \\
\text { et al., 2002) }\end{array}$ & 4.9 & $216.8 \pm 0.1$ & $\mathrm{~T}_{\mathrm{m}} 118.7 \pm 1.6$ \\
\hline
\end{tabular}


4-Aminobenzoic

Acid (4-ABA)

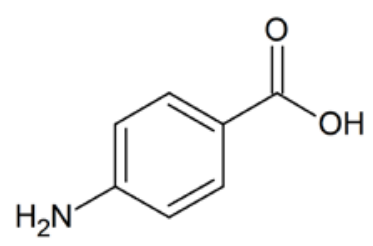

Salicylic Acid (SA)

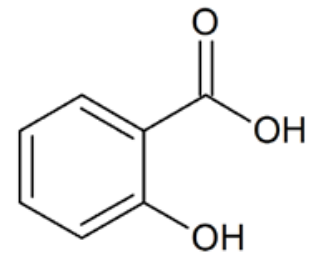

2.4, 4.9 (van

5.4

de Graaf et al.,

1981)

3.0

2.2

(Stoimenovski

et al., 2010)
$187.9 \pm 1.0$

$\mathrm{T}_{\mathrm{m}} 122.9 \pm 0.1$ 


\begin{tabular}{lll}
\hline$\chi$ MET & $\begin{array}{l}\text { Tg } \\
\left({ }^{\circ} \mathbf{C}\right)\end{array}$ & $\begin{array}{l}\text { Tm (end) } \\
\left({ }^{\circ} \mathbf{C}\right)\end{array}$ \\
\hline 0.00 & - & $152.5 \pm 2.9$ \\
0.10 & $-41.2 \pm 3.5$ & $145.4 \pm 3.3$ \\
0.20 & $-35.6 \pm 2.2$ & $124.1 \pm 1.7$ \\
0.33 & $-36.4 \pm 5.9$ & $103.8 \pm 8.2$ \\
0.40 & $-39.5 \pm 5.2$ & $93.0 \pm 4.8$ \\
0.50 & $-39.7 \pm 3.4$ & - \\
0.60 & $-41.3 \pm 2.4$ & $88.6 \pm 6.3$ \\
0.67 & $-40.4 \pm 4.6$ & $106.6 \pm 5.0$ \\
0.70 & $-38.1 \pm 1.4$ & $123.7 \pm 2.9$ \\
0.80 & $-40.7 \pm 0.9$ & $156.5 \pm 1.1$ \\
0.90 & - & $158.8 \pm 2.4$ \\
1.00 & - & $169.5 \pm 1.0$ \\
\hline
\end{tabular}




\begin{tabular}{lll}
\hline & IR Frequency $\left(\mathbf{c m}^{-\mathbf{1}}\right)$ & Band Assignment \\
\hline Metronidazole & 3209 & O-H stretch (intra H-bonded) \\
& 3099 & Aromatic C-H stretch \\
& 1533,1484 & N-O asymmetric stretch \\
& 1273,1264 & C-N stretch \\
& 1073 & C-O stretch \\
Maleic Acid & 2871 & $=$ C-H bend \\
& 1704 & O-H stretch \\
MET-MA & 1633 & C=O stretch \\
THEDES & 3427 & C=C stretch \\
$(\boldsymbol{\chi}$ MET $=\mathbf{0 . 5 0})$ & 1712 & O-H stretch (free MET) \\
& 1619 & O-H stretch (H-bonded MA) \\
& 1580 & C=O stretch (broadened) \\
& & C=C stretch \\
& & COO- stretch \\
\hline
\end{tabular}




\begin{tabular}{lllll}
\hline & $\begin{array}{l}\text { DP (\%) } \\
\mathbf{1 0} \text { mins }\end{array}$ & $\mathbf{2 0}$ mins & $\mathbf{4 5}$ mins & $\mathbf{1 2 0}$ mins \\
\hline MET & $0.2 \pm 1.3 \times 10^{-2}$ & $1.3 \pm 0.1$ & $5.1 \pm 2.5$ & $98.1 \pm 10.2$ \\
MET-MA 1:1 LAG & $36.8 \pm 10.8$ & $87.1 \pm 7.4$ & $89.3 \pm 1.2$ & $103.9 \pm 4.8$ \\
MET-MA 1:1 HME & $69.3 \pm 6.9$ & $82.6 \pm 7.3$ & $98.0 \pm 4.5$ & $101.6 \pm 1.3$ \\
\hline
\end{tabular}

600

601 Table 5 Drug percentage (DP \%) and dissolution rate (DR \%/day) at particular timepoints for the data presented in Figure 60213.

\begin{tabular}{lllllll}
\hline & DP (\%) & \multicolumn{5}{c}{ DR (\%/day) } \\
& Day 1 & Day 2 & Day 7 & Day 1 & Day 2 & Day 7 \\
\hline MET (10 \% w/w) & $11.7 \pm 1.5$ & $17.7 \pm 1.6$ & $35.6 \pm 2.7$ & $11.7 \pm 1.5$ & $8.9 \pm 0.8$ & $5.1 \pm 0.4$ \\
MET (20 \% w/w) & $14.9 \pm 0.6$ & $18.4 \pm 1.5$ & $43.0 \pm 3.6$ & $14.9 \pm 0.6$ & $9.2 \pm 0.7$ & $6.1 \pm 0.5$ \\
MET-MA (10 \% & $16.5 \pm 1.9$ & $27.5 \pm 2.1$ & $73.6 \pm 3.9$ & $16.5 \pm 1.9$ & $13.6 \pm 1.0$ & $10.4 \pm 0.6$ \\
w/w MET) & & & & & & \\
MET-MA (20 \% & $36.0 \pm 0.2$ & $55.6 \pm 0.8$ & $83.9 \pm 4.1$ & $36.0 \pm 0.2$ & $27.8 \pm 0.4$ & $12.0 \pm 0.6$ \\
w/w MET) & & & & & & \\
\hline
\end{tabular}

603 
604

605

606

607

608

609

610

611

612

613

614

615

616

617

618

619

620

621

622

623

624

625

626

627

628

629

630

631

632

633

634

635

\section{REFERENCES}

Abbott, A.P., Ahmed, E.I., Prasad, K., Qader, I.B., Ryder, K.S., 2017. Liquid pharmaceuticals formulation by eutectic formation. Fluid Phase Equilib. 448, 2-8. https://doi.org/10.1016/j.fluid.2017.05.009

Abbott, A.P., Boothby, D., Capper, G., Davies, D.L., Rasheed, R.K., 2004. Deep Eutectic Solvents formed between choline chloride and carboxylic acids: Versatile alternatives to ionic liquids. J. Am. Chem. Soc. 126, 9142-9147. https://doi.org/10.1021/ja048266j

Alster, T., 2013. Review of Lidocaine/Tetracaine Cream as a Topical Anesthetic for Dermatologic Laser Procedures. Pain Ther. 2, 11-19. https://doi.org/10.1007/s40122013-0013-z

Aroso, I.M., Craveiro, R., Rocha, Â., Dionísio, M., Barreiros, S., Reis, R.L., Paiva, A., Duarte, A.R.C., 2015. Design of controlled release systems for THEDES - Therapeutic deep eutectic solvents, using supercritical fluid technology. Int. J. Pharm. 492, 73-79. https://doi.org/10.1016/j.ijpharm.2015.06.038

Aroso, I.M., Silva, J.C., Mano, F., Ferreira, A.S.D., Dionísio, M., Sá-Nogueira, I., Barreiros, S., Reis, R.L., Paiva, A., Duarte, A.R.C., 2016. Dissolution enhancement of active pharmaceutical ingredients by therapeutic deep eutectic systems. Eur. J. Pharm. Biopharm. https://doi.org/10.1016/j.ejpb.2015.11.002

Bica, K., Shamshina, J., Hough, W.L., MacFarlane, D.R., Rogers, R.D., 2011. Liquid forms of pharmaceutical co-crystals: Exploring the boundaries of salt formation. Chem. Commun. 47, 2267-2269. https://doi.org/10.1039/c0cc04485g

Bryan, H.A., Alster, T.S., Koppel, R.A., 2002. The S-Caine peel: A novel topical anesthetic for cutaneous laser surgery. Dermatologic Surg. 28, 999-1003. https://doi.org/10.1046/j.1524-4725.2002.02079.x

Centers for Disease Control and Prevention, 2015. Bacterial Vaginosis - 2015 STD Treatment Guidelines [WWW Document]. CDC.

Cherukuvada, S., Nangia, A., 2013. Eutectics as improved pharmaceutical materials: design, properties and characterization. Chem. Commun. 50, 906-923. https://doi.org/10.1039/c3cc47521b

Chiarinelli, J., Casavola, A.R., Castrovilli, M.C., Bolognesi, P., Cartoni, A., Wang, F., Richter, R., Catone, D., Tosic, S., Marinkovic, B.P., Avaldi, L., 2019. Radiation damage mechanisms of chemotherapeutically active nitroimidazole derived compounds. Front. Chem. 7, 1- 
Crawford, D.E., Wright, L.A., James, S.L., Abbott, A.P., 2016. Efficient continuous synthesis of high purity deep eutectic solvents by twin screw extrusion. Chem. Commun. 52, 42154218. https://doi.org/10.1039/C5CC09685E

Cunningham, F.E., Kraus, D.M., Brubaker, L., Fischer, J.H., 1994. Pharmacokinetics of intravaginal metronidazole gel. J. Clin. Pharmacol. 34, 1060-1065.

Dang, N.T.T., Turner, M.S., Coombes, A.G.A., 2013. Development of intra-vaginal matrices from polycaprolactone for sustained release of antimicrobial agents. J. Biomater. Appl. 28, 74-83. https://doi.org/10.1177/0885328212437393

Darwish, A., Elnshar, E.M., Hamadeh, S.M., Makarem, M.H., 2007. Treatment options for bacterial vaginosis in patients at high risk of preterm labor and premature rupture of

Dean, P.M., Turanjanin, J., Yoshizawa-Fujita, M., MacFarlane, D.R., Scott, J.L., 2009. membranes. J. Obstet. Gynaecol. Res. 33, 781-787. https://doi.org/10.1111/j.1447-

Etter, M.C., 1991. Hydrogen bonds as design elements in organic chemistry. J. Phys. Chem. https://doi.org/10.1021/j100165a007

Fernando, H.V., Chan, L.L., Dang, N., Santhanes, D., Banneheke, H., Nalliah, S., Coombes, A.G.A., 2019. Controlled delivery of the antiprotozoal agent (tinidazole) from intravaginal polymer matrices for treatment of the sexually transmitted infection, trichomoniasis. Pharm. Dev. Technol. 24, 348-356. https://doi.org/10.1080/10837450.2018.1481430 Martens, M., 2000. Metronidazole for bacterial vaginosis: A comparison of vaginal gel vs. oral therapy. J. Reprod. Med. Obstet. Gynecol. https://doi.org/10.1097/00006254- 
668

669

670

671

672

673

674

675

676

677

678

679

680

681

682

683

684

685

686

687

688

689

690

691

692

693

694

695

696

697

698

699

Hollingsworth, C.A., Seybold, P.G., Hadad, C.M., 2002. Substituent effects on the electronic structure and pKa of benzoic acid. Int. J. Quantum Chem. 90, 1396-1403.

$$
\text { https://doi.org/10.1002/qua.10362 }
$$

Hyun, S.M., Lee, B.J., Abuzar, S.M., Lee, S., Joo, Y., Hong, S.H., Kang, H., Kwon, K.A., Velaga, S., Hwang, S.J., 2019. Preparation, characterization, and evaluation of celecoxib eutectic mixtures with adipic acid/saccharin for improvement of wettability and dissolution rate. Int. J. Pharm. 554, 61-71.

https://doi.org/10.1016/j.ijpharm.2018.10.044

Jones, A., 2019. Bacterial Vaginosis: A Review of Treatment, Recurrence, and Disparities. J. Nurse Pract. https://doi.org/10.1016/j.nurpra.2019.03.010

Kastelic, J., Hodnik, Ž., Šket, P., Plavec, J., Lah, N., Leban, I., Pajk, M., Planinšek, O., Kikelj, D., 2010. Fluconazole cocrystals with dicarboxylic acids. Cryst. Growth Des. 10, 4943-4953. https://doi.org/10.1021/cg1010117

Lan, S.F., Kehinde, T., Zhang, X., Khajotia, S., Schmidtke, D.W., Starly, B., 2013. Controlled release of metronidazole from composite poly- $\varepsilon$-caprolactone/alginate ( $\mathrm{PCL} /$ alginate) rings for dental implants. Dent. Mater. 29, 656-665.

https://doi.org/10.1016/j.dental.2013.03.014

Li, S., Yu, T., Tian, Y., Lagan, C., Jones, D.S., Andrews, G.P., 2018. Mechanochemical Synthesis of Pharmaceutical Cocrystal Suspensions via Hot Melt Extrusion: Enhancing Cocrystal Yield. Mol. Pharm. 15, 3741-3754.

https://doi.org/10.1021/acs.molpharmaceut.7b00979

Li, S., Yu, T., Tian, Y., McCoy, C.P., Jones, D.S., Andrews, G.P., 2016. Mechanochemical Synthesis of Pharmaceutical Cocrystal Suspensions via Hot Melt Extrusion: Feasibility Studies and Physicochemical Characterization. Mol. Pharm. 13, 3054-3068.

https://doi.org/10.1021/acs.molpharmaceut.6b00134

Maçôas, E.M.S., Fausto, R., Lundell, J., Pettersson, M., Khriachtchev, L., Räsänen, M., 2001. A matrix isolation spectroscopic and quantum chemical study of fumaric and maleic acid. J. Phys. Chem. A 105, 3922-3933. https://doi.org/10.1021/jp003802p

Martins, I.C.B., Sardo, M., Santos, S.M., Fernandes, A., Antunes, A., André, V., Mafra, L., Duarte, M.T., 2016. Packing Interactions and Physicochemical Properties of Novel Multicomponent Crystal Forms of the Anti-Inflammatory Azelaic Acid Studied by X-ray and Solid-State NMR. Cryst. Growth Des. 16, 154-166. 
Mishell, D.R., Lumkin, M.E., 1970. Contraceptive effect of varying dosages of progestogen in silastic vaginal rings. Fertil. Steril. 21, 99-103. https://doi.org/10.1016/s00150282(16)37333-2

704

705

706

707

708

709

710

711

712

713

714

715

716

Myer, L., Denny, L., Telerant, R., Souza, M. de, Wright, Jr., T.C., Kuhn, L., 2005. Bacterial Vaginosis and Susceptibility to HIV Infection in South African Women: A Nested CaseControl Study. J. Infect. Dis. 192, 1372-1380. https://doi.org/10.1086/462427

Owen, D.H., Katz, D.F., 1999. A vaginal fluid simulant. Contraception 59, 91-95. https://doi.org/10.1016/S0010-7824(99)00010-4

Pal, K., Roy, S., Behera, B., Kumar, N., Sagiri, S., Ray, S., 2011. Bacterial vaginosis: Etiology and modalities of treatment-A brief note. J. Pharm. Bioallied Sci. 3, 496. https://doi.org/10.4103/0975-7406.90102

Pathak, M., Coombes, A.G.A., Ryu, B.M., Cabot, P.J., Turner, M.S., Palmer, C., Wang, D., Steadman, K.J., 2018. Sustained Simultaneous Delivery of Metronidazole and Doxycycline From Polycaprolactone Matrices Designed for Intravaginal Treatment of Pelvic Inflammatory Disease. J. Pharm. Sci. 107, 863-869. https://doi.org/10.1016/j.xphs.2017.09.033

Pathak, M., Coombes, A.G.A., Turner, M.S., Palmer, C., Wang, D., Steadman, K.J., 2015. Investigation of polycaprolactone matrices for intravaginal delivery of doxycycline. J. Pharm. Sci. 104, 4217-4222. https://doi.org/10.1002/jps.24652

Pathak, M., Turner, M., Palmer, C., Coombes, A.G.A., 2014. Evaluation of polycaprolactone matrices for the intravaginal delivery of metronidazole in the treatment of bacterial vaginosis. J. Biomater. Appl. 29, 354-363. https://doi.org/10.1177/0885328214528256

Pedro, S.N., Freire, M.G., Freire, C.S.R., Silvestre, A.J.D., 2019. Deep eutectic solvents comprising active pharmaceutical ingredients in the development of drug delivery systems. Expert Opin. Drug Deliv. https://doi.org/10.1080/17425247.2019.1604680

Promadej-Lanier, N., Smith, J.M., Srinivasan, P., McCoy, C.F., Butera, S., Woolfson, A.D., Malcolm, R.K., Otten, R.A., 2009. Development and evaluation of a vaginal ring device for sustained delivery of HIV microbicides to non-human primates. J. Med. Primatol. 38, 263-271. https://doi.org/10.1111/j.1600-0684.2009.00354.x

Ramanujam, R., Sundaram, B., Janarthanan, G., Devendran, E., Venkadasalam, M., John Milton, M.C., 2018. Biodegradable Polycaprolactone Nanoparticles Based Drug Delivery 

Systems: A Short Review. Biosci. Biotechnol. Res. Asia. https://doi.org/10.13005/bbra/2676

Ramukutty, S., Ramachandran, E., 2012. Crystal growth by solvent evaporation and characterization of metronidazole. J. Cryst. Growth 351, 47-50. https://doi.org/10.1016/j.jcrysgro.2012.04.017

Raymond, B., 2019. Five rules for resistance management in the antibiotic apocalypse, a road map for integrated microbial management. Evol. Appl. 12, 1079-1091. https://doi.org/10.1111/eva.12808

Rim, P.B., Runt, J.P., 1984. Melting Point Depression in Crystalline/Compatible Polymer Blends. Macromolecules 17, 1520-1526. https://doi.org/10.1021/ma00138a017

Shamshina, J.L., Barber, P.S., Rogers, R.D., 2013. Ionic liquids in drug delivery. Expert Opin. Drug Deliv. 10, 1367-1381. https://doi.org/10.1517/17425247.2013.808185

Sheldon, R.A., 2017. The: E factor 25 years on: The rise of green chemistry and sustainability. Green Chem. 19, 18-43. https://doi.org/10.1039/c6gc02157c

Smith, A., 2018. Metronidazole resistance: A hidden epidemic? Br. Dent. J. 224, 1-2. https://doi.org/10.1038/sj.bdj.2018.221

Steiner, T., Desiraju, G.R., 1999. The weak hydrogen bond in structural chemistry and biology. Oxford University Press, New York.

Stoimenovski, J., MacFarlane, D.R., Bica, K., Rogers, R.D., 2010. Crystalline vs. ionic liquid salt forms of active pharmaceutical ingredients: A position paper. Pharm. Res. 27, 521-526. https://doi.org/10.1007/s11095-009-0030-0

Stuart, B.H., 2004. Infrared Spectroscopy: Fundamentals and Applications. John Wiley \& Sons. https://doi.org/10.1002/0470011149

Taylor, L.S., Zografi, G., 1998. Sugar-Polymer Hydrogen Bond Interactions in Lyophilized Amorphous Mixtures. J. Pharm. Sci. 87, 1615-1621.

Turgut, E.H., Ozyazici, M., 2004. Bioavailability File: Metronidazole. Fabad J. Pharm. Sci. 29, 39-49.

van de Graaf, B., Hoefnagel, A.J., Wepster, B.M., 1981. Substituent Effects. 7.1 Microscopic Dissociation Constants of 4-Aminoand 4-(Dimethylamino)benzoic Acid. J. Org. Chem. 46, 653-657. https://doi.org/10.1021/jo00317a002

Wagner, K.A., Gibbon, K.J., Strom, T.L., Kurian, J.R., Trepanier, L.A., 2006. Adverse effects of EMLA (lidocaine/prilocaine) cream and efficacy for the placement of jugular catheters 
in hospitalized cats. J. Feline Med. Surg. 8, 141-144.

https://doi.org/10.1016/j.jfms.2005.10.002

Wan, Y., Xiao, B., Dalai, S., Cao, X., Wu, Q., 2009. Development of polycaprolactone/chitosan blend porous scaffolds. J. Mater. Sci. Mater. Med. 20, 719-724.

https://doi.org/10.1007/s10856-008-3622-z

Wang, H., Gurau, G., Shamshina, J., Cojocaru, O.A., Janikowski, J., MacFarlane, D.R., Davis, J.H., Rogers, R.D., 2014. Simultaneous membrane transport of two active pharmaceutical ingredients by charge assisted hydrogen bond complex formation. Chem. Sci. 5, 3449. https://doi.org/10.1039/C4SC01036A

Welsh, N.R., Malcolm, R.K., Devlin, B., Boyd, P., 2019. Dapivirine-releasing vaginal rings produced by plastic freeforming additive manufacturing. Int. J. Pharm. 572, 1-8. https://doi.org/10.1016/j.ijpharm.2019.118725

Wu, P., Grainger, D.W., 2006. Drug/device combinations for local drug therapies and infection prophylaxis. Biomaterials 27, 2450-2467. https://doi.org/10.1016/j.biomaterials.2005.11.031

Yalkowsky, S.H., He, Y., Jain, P., 2010. Handbook of Aqueous Solubility Data, Second Edi. ed. CRC Press, Taylor \& Francis Group.

Yamashita, H., Hirakura, Y., Yuda, M., Terada, K., 2014. Coformer Screening Using Thermal Analysis Based on Binary Phase Diagrams. Pharm. Res. 31, 1946-1957. https://doi.org/10.1007/s11095-014-1296-4

Zeitsch, K.J., 2000. Maleic Acid, in: The Chemistry and Technology of Furfural and Its Many By-Products. Elsevier, pp. 225-228. https://doi.org/10.1007/978-3-540-71095-0_6254

Zhang, L., Huang, Y., Zhou, Y., Buckley, T., Wang, H.H., 2013. Antibiotic Administration Routes Significantly Influence the Levels of Antibiotic Resistance in Gut Microbiota. Antimicrob. Agents Chemother. https://doi.org/10.1128/aac.00670-13

Zheng, K., Li, A., Wu, W., Qian, S., Liu, B., Pang, Q., 2019. Preparation, characterization, in vitro and in vivo evaluation of metronidazole-gallic acid cocrystal: A combined experimental and theoretical investigation. J. Mol. Struct. 1197, 727-735. https://doi.org/10.1016/j.molstruc.2019.07.102 